8-1-2014

\title{
Breach of tolerance: primary biliary cirrhosis.
}

\author{
Lifeng Wang \\ Research Center for Biological Therapy, Institute of Translational Hepatology, Beijing 302 Hospital, Beijing, \\ China
}

\section{Fu-Sheng Wang}

Research Center for Biological Therapy, Institute of Translational Hepatology, Beijing 302 Hospital, Beijing, China

Christopher Chang

Department of Pediatrics, Thomas Jefferson University, Nemours/A.I. DuPont Hospital for Children, Wilmington, $D E$, United States

M Eric Gershwin

Division of Rheumatology, Allergy and Clinical Immunology, University of California, Davis School of Medicine, Davis, CA, United States

Follow this and additional works at: https://jdc.jefferson.edu/medgenfp

Part of the Other Medical Specialties Commons

Let us know how access to this document benefits you

\section{Recommended Citation}

Wang, Lifeng; Wang, Fu-Sheng; Chang, Christopher; and Gershwin, M Eric, "Breach of tolerance: primary biliary cirrhosis." (2014). Department of Medical Genetics Faculty Papers. Paper 9. https://jdc.jefferson.edu/medgenfp/9

This Article is brought to you for free and open access by the Jefferson Digital Commons. The Jefferson Digital Commons is a service of Thomas Jefferson University's Center for Teaching and Learning (CTL). The Commons is a showcase for Jefferson books and journals, peer-reviewed scholarly publications, unique historical collections from the University archives, and teaching tools. The Jefferson Digital Commons allows researchers and interested readers anywhere in the world to learn about and keep up to date with Jefferson scholarship. This article has been accepted for inclusion in Department of Medical Genetics Faculty Papers by an authorized administrator of the Jefferson Digital Commons. For more information, please contact: JeffersonDigitalCommons@jefferson.edu. 


\title{
Breach of Tolerance: Primary Biliary Cirrhosis
}

\author{
Lifeng Wang, MD, $\mathrm{PhD}^{1} \quad$ Fu-Sheng Wang, MD, $\mathrm{PhD}^{1}$ \\ ${ }^{1}$ Research Center for Biological Therapy, The Institute of Translational
Hepatology, Beijing 302 Hospital, Beijing, China
${ }^{2}$ Division of Allergy and Immunology, Department of Pediatrics,
Thomas Jefferson University, Nemours/A.I. duPont Hospital for
Children, Wilmington, Delaware
${ }^{3}$ Division of Rheumatology, Allergy and Clinical Immunology,
University of California at Davis School of Medicine, Davis, California
}

Christopher Chang, MD, $\mathrm{PhD}^{2}$

M. Eric Gershwin, MD ${ }^{3}$

Address for correspondence M. Eric Gershwin, MD, Division of Rheumatology, Allergy and Clinical Immunology, University of California at Davis School of Medicine, Davis, California (e-mail: megershwin@ucdavis.edu).

Semin Liver Dis 2014;34:297-317.

\author{
Abstract \\ Keywords \\ - apoptosis \\ - autoreactive T cells \\ - antimitochondrial \\ antibodies \\ - liver-tolerance effect \\ - pyruvate \\ dehydrogenase \\ complex
}

In primary biliary cirrhosis (PBC), the breach of tolerance that leads to active disease involves a disruption in several layers of control, including central tolerance, peripheral anergy, a "liver tolerance effect," and the action of T regulatory cells and their related cytokines. Each of these control mechanisms plays a role in preventing an immune response against self, but all of them act in concert to generate effective protection against autoimmunity without compromising the ability of the host immune system to mount an effective response to pathogens. At the same time, genetic susceptibility, environmental factors, including infection agents and xenobiotics, play important roles in breach of tolerance in the development of PBC.
Primary biliary cirrhosis (PBC) is a chronic cholestatic liver disease characterized by immunomediated destruction of the small- and medium-sized intrahepatic bile ducts, mediated by a selective loss of self-tolerance. ${ }^{1}$ Epidemiological and genetic studies indicate that $\mathrm{PBC}$ is triggered in genetically susceptible individuals following exposure to environmental factors, including microbes and chemical compounds. ${ }^{2,3}$ Loss of tolerance occurs either via molecular mimicry and/or the formation of neoantigens and the development of cross reactivity. ${ }^{4}$ This process results from dysfunction in both innate and adaptive immunity, leading to the expansion of autoreactive T- and B-lymphocyte populations. ${ }^{5}$ In PBC, the multiorchestrated immune effector mechanisms lead to bile duct injury.

\section{Immune Tolerance and the "Liver Tolerance Effect"}

In the 1890s, Paul Ehrlich described a phenomenon in which a host immune system turns on itself, attacking and damaging its own organs and tissues. He coined the term "horror autotoxicus" to describe how the phenomenon is teleologi- cally impossible and that nature would or should not allow this to happen. As a result, despite research supporting the existence of autoimmunity early in the $20^{\text {th }}$ century, little attention was paid to the concept of immune tolerance. The discipline of autoimmunity was eventually recognized by the 1940s, and in the ensuing 20 years, an appreciation of the pathogenesis of rheumatoid arthritis and systemic lupus erythematosus was increasingly attributed to an autoimmune phenomenon. In 1948, Frank Macfarlane Burnet deduced the nature of immunological inertness to self, first naming this as "tolerance" and then proposing it to be a characteristic acquired in developmental life rather than innately as earlier believed., ${ }^{6,7}$ In 1953, Medawar and his colleagues experimentally demonstrated the induction of immune tolerance in inbred mice. ${ }^{8}$ Ultimately, the conception of immune tolerance was defined as an ability of the immune system to prevent itself from targeting self-molecules, cells, or tissues; this has led to seminal research in our understanding of autoimmunity. ${ }^{9}$

The hallmark of the immune system is its ability to maintain this tolerance to self-antigens, and yet still be able to mount effective immune responses against pathogens and
Issue Theme Primary Biliary Cirrhosis; Guest Editor, Pietro Invernizzi, MD, PhD
Copyright (c) 2014 by Thieme Medical Publishers, Inc., 333 Seventh Avenue, New York, NY 10001, USA.

Tel: +1(212) 584-4662.
DOI http://dx.doi.org/ 10.1055/s-0034-1383729. ISSN $0272-8087$. 
malignant cells (danger signals). Breaking the balance between tolerance and immunity can lead to disease manifestations, resulting in infections, neoplasia, or autoimmunity. To avoid harmful self-reactivity, self-tolerance within the Tand B-cell repertoire are achieved through central and peripheral tolerance mechanisms.

Central tolerance in the thymus and bone marrow play key roles in shaping immune system homeostasis, especially in early life. In the thymus, with no marked reactivity against self-peptides, developing lymphocytes undergo positive selection in the thymic cortex, then become mature lymphocytes and enter the circulation. Conversely, developing lymphocytes with marked reactivity against self-peptides are negatively selected and deleted in the thymic medulla. ${ }^{10-14}$ After exiting the thymus, mature $\mathrm{T}$ cells are subjected to secondary selection (peripheral tolerance) by which the majority of self-reactive $\mathrm{T}$ cells are deleted or rendered anergic. $^{15,16}$ Meanwhile, when immature B cells express surface IgM that recognize ubiquitous self-cell-surface antigens, they are eliminated by a process known as clonal deletion or anergy. ${ }^{17}$ Autoreactive B cells can escape deletion by a process known as receptor editing. ${ }^{18,19}$ Mature B cells are also under the control of peripheral tolerance. ${ }^{20}$

Abundant evidence suggests that even under the regulation of central and peripheral tolerance, small numbers of potentially hazardous self-reactive lymphocytes still can "leak out" into the periphery in normal individuals. ${ }^{21,22}$ But these residual self-reactive $\mathrm{T}$ cells normally remain in an inactive state due to several factors, including lack of costimulation from antigen-presenting cells, low avidities of their T-cell receptors (TCRs) for self-antigens, or seclusion of selfantigens. ${ }^{23}$ At the same time, mature self-reacting B cells may survive intact and rarely be activated because they need costimulatory signals from $T$ cells, as well as the presence of its recognized antigen to proliferate and produce antibodies.

In addition to these passive mechanisms, evidence indicates that suppressive regulatory mechanisms also exist. $\mathrm{CD} 4+\mathrm{CD} 25+\mathrm{T}$ regulatory cells (Tregs) are immune regulatory cells that play an important role in immune homeostasis. These cells are involved in the maintenance of peripheral selftolerance and downregulation of immune responses. ${ }^{24-26}$ PDCD5 acetylates FOXP3 and affects Treg cell modulation of immune function, thereby playing a role in the development of autoimmune disease. ${ }^{27}$

Liver tissue itself also possesses the ability to mediate local and systemic tolerance to self and foreign antigens. ${ }^{28}$ This is known as the "liver tolerance effect." The liver is a depot for clearance of toxins and metabolic products that result from physiologic and pathogenic processes. Thus, there is a need to prevent activation of the immune system by exposure to "nonpathogenic" molecules (including food components) and microorganisms (gut microflora), while continuing to mount an effective immune response against pathogens. ${ }^{29,30}$ Nonparenchymal liver cells including the liver sinusoidal endothelial cells, resident DCs, Kupffer cells, and hepatic stellate cells are likely responsible for hepatic tolerance. These cells can generate anti-inflammatory cytokines including IL-10 and TGF $\beta$ or express the negative costimulators of T-cell activation that mediate immune suppression, such as programmed cell death ligand-1 (PD-L1). ${ }^{31,32}$ In addition, hepatocytes and Treg cells are also involved in mediating T-cell tolerance in the liver.

The normal physiologic mechanisms of immune tolerance should prevent autoimmune diseases. The concept of autoimmunity is often thought to require the presence of autoantibodies (antibodies directed against normal self-tissues or substances). ${ }^{33,34}$ However, autoimmunity may exist in the absence of a known autoantigen. Autoimmunity generally results from a defect in central tolerance mechanisms that allows the generation and proliferation of a limited number of autoreactive cells, which can mature and enter the periphery. However, it has been repeatedly demonstrated in animal and human studies that the presence of autoreactive cells does not universally lead to autoimmune disease. A breach of tolerance that occasionally occurs during the process of mounting an immune response to a pathogen is often, but not always the trigger for the development of autoimmune diseases. Autoimmune diseases are generally classified on the basis of the organ or tissue involved. Autoimmune diseases that are restricted to specific organs of the body are known as organ-specific autoimmune diseases, including type 1 diabetes mellitus, multiple sclerosis, $\mathrm{PBC}$, and psoriasis. Conversely, if many tissues of the body are affected, the disease is regarded as a systemic autoimmune disease, such as systemic lupus erythematosus and rheumatoid arthritis.

\section{Primary Biliary Cirrhosis and a Breach of Tolerance}

In 1851, Addison and Gull first described nonobstructive biliary cirrhosis. The disease was further characterized clinically by Ahrens et al in 1950. After a considerable period of research inactivity, a cDNA encoding the autoantigen targeted by these antimitochondrial antibodies (AMAs) was cloned in 1987 by Gershwin and colleagues. ${ }^{35}$ Subsequently, the antigen was identified as the E2 subunit (E2) of the pyruvate dehydrogenase complex (PDC). ${ }^{36}$ More recently, other autoantibodies have been detected in $\mathrm{PBC}$ patients, including those directed against the nuclear pore complex (NPC). ${ }^{37} \mathrm{~A}$ series of interrelated immunoreactive events have been discovered to occur in primary biliary cirrhosis, which upon characterization will contribute to our understanding of the mechanisms of breach of tolerance (-Fig. 1).

Primary biliary cirrhosis, with the presence of autoantibodies (AMAs), PDC-E2-specific autoreactive CD4, CD8 T cells, autoreactive $B$ lymphocytes in liver tissue, and three separate genetically based mouse models, ${ }^{38-40}$ fulfills the criteria for an autoimmune disease. ${ }^{41}$ Autoimmune mechanisms of PBC are multifactorial, ${ }^{42}$ consisting of a breakdown in central or peripheral tolerance, as well as the aforementioned liver tolerance effect.

Specifically, the loss of tolerance in PBC patients may occur as a result of three main conceptual mechanisms: (1) molecular mimicry and the presence of neoantigens, developed through cross reactivity to PDC-E2; (2) a genetic 


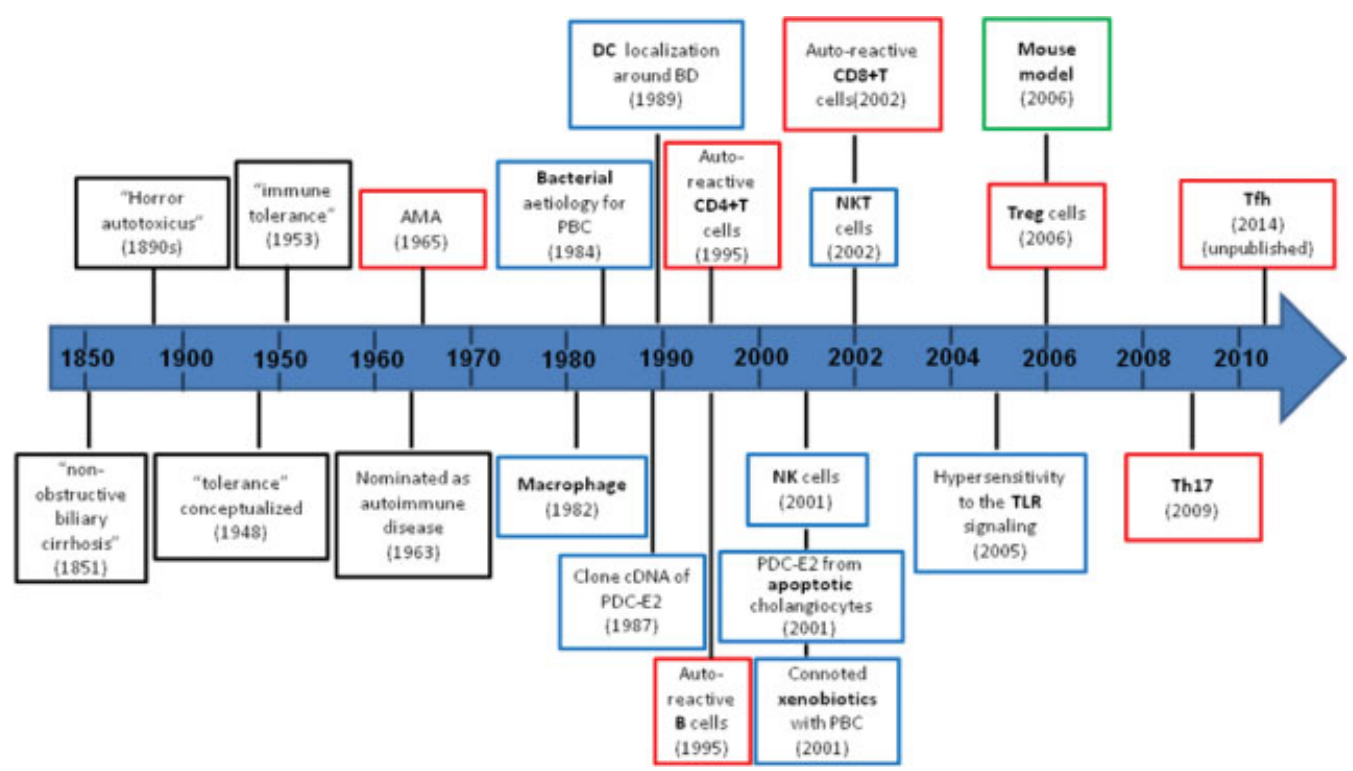

Fig. 1 Timeline of identifying immune parameters in primary biliary cirrhosis (PBC). Black, clinical immunology-related events and conception; blue, innate immunity; red, adaptive immunity; green, PBC mouse models. AMA, antimitochondrial antibody; BD, biliary ducts; DC, dendritic cell; NK, natural killer; NKT, Natural killer T; TLR, Toll-like receptor.

susceptibility, responsible for inheritable abnormalities in the regulation of immune responses; and (3) an imbalance in the immune system, leading to an overactive innate immune system, which inappropriately activates nonspecific immune responses that lead to the expansion of autoreactive populations of T and B lymphocytes (-Fig. 2).

\section{Mitochondrial Autoantigens in Primary Biliary Cirrhosis}

The 2-oxoacid dehydrogenase complex (2-OADC) autoantigens are multienzyme complexes essential in the mitochondrial respiratory chain. ${ }^{43}$ This enzyme family includes three

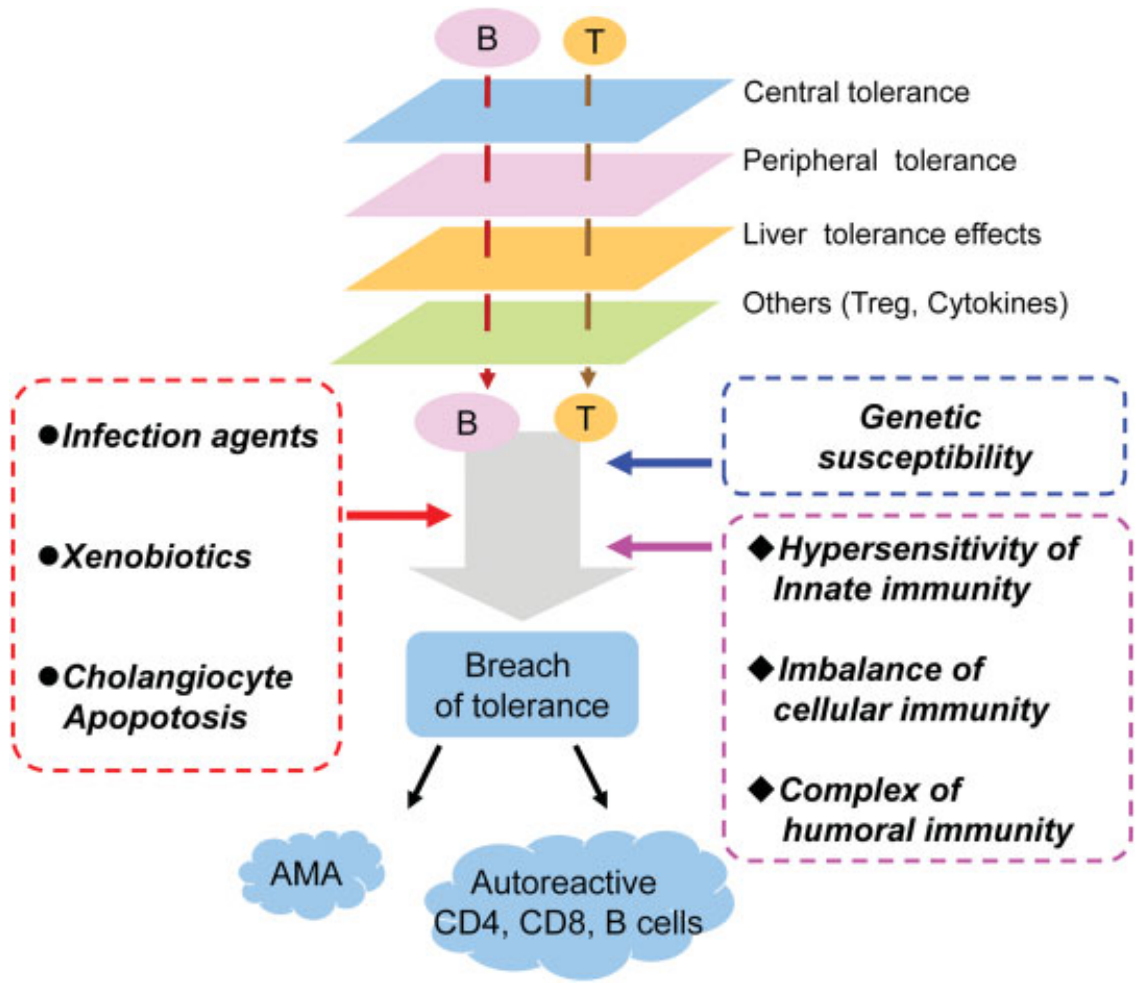

Fig. 2 Mechanisms that are involved in breaching immune tolerance in primary biliary cirrhosis. The breach of tolerance that leads to active disease involves a disruption in several layers of control, including central tolerance, peripheral anergy, a "liver tolerance effect," and the action of T regulatory cells and their related cytokines. At the same time, genetic susceptibility, environmental factors, including infection agents and xenobiotics, also play important roles in breach tolerance. 
complexes: PDC, the 2-oxo glutarate dehydrogenase complex (OGDC), and the branched chain 2-oxoacid dehydrogenase complex (BCOADC). Each of the three complexes consists of three subunits: E1, E2, and E3. Antimitochondrial antibodies specifically recognize the lipoylated domains of the 2-OADC family of enzymes, and all immunodominant epitopes contain an ExDKA (glutamic acid -E-, $\mathrm{x}$, aspartic acid, -D-, lysine $\mathrm{k}-$, and alanine $-\mathrm{A}-$ ) motif, with lipoic acid attached to $\mathrm{K}$ at position 173 . This configuration is necessary and/or sufficient for antigen recognition. Interestingly, there are only five proteins in mammals that contain lipoic acid, and four of the five are autoantigens in PBC. Among the 2-OADC constituents, the major autoantigen is the PDC-E2, which was the antigen first cloned in $1987^{35}$; less frequent autoantigens include OADC-E2, BCOADC-E2, and E3BP. ${ }^{44}$

In autoimmunity, the paradox is that autoantigens are unable to elicit a primary immune response themselves, but can be recognized as targets for effector T cells stimulated by a pathogenic cross-reactive epitope. To break self-tolerance to the autoantigen, the epitope mimic or mimotope needs to induce activation and proliferation rather than anergy of autoreactive T cells. Subsequently, the autoantigen presented by the host cells of a certain tissue must be recognized by reactive epitope-specific $T$ cells. In the case of $\mathrm{PBC}$, either a mimotope carried by a microbe or a neoantigen generated by xenobiotic-modified self-antigen can mimic mitochondrial proteins, and subsequently may activate autoreactive lymphocytes that have leaked out into the peripheral repertoire. The process may become self-perpetuating because of the cross-reactive unmodified self-antigens (-Fig. 3). ${ }^{45}$

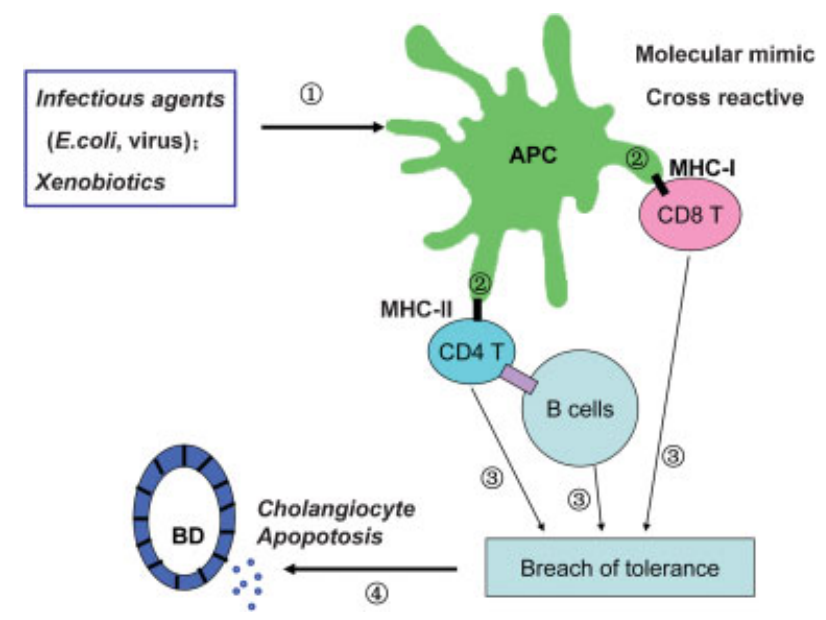

Fig. 3 Molecular mimicry of PDC-E2 helps breach tolerance in primary biliary cirrhosis (PBC) patients. (1) Infectious agents (E. coli, viral pathogens) and xenobiotics can be recognized and phagocytosed by antigen-presenting cells (APCs); (2) APCs process and present molecular mimicry of PDC-E2 to CD4 or CD8 T cells by MHC-II or MHC-I; (3) autoreactive CD4 T, CD8 T cells are activated, and CD4 T cells provide help to autoreactive $B$ cells to produce antimitochondrial antibodies (AMA), which lead to the breach of tolerance; (4) intact PDC-E2 released from biliary epithelial cells recognized by reactive epitopespecific $T$ cells lead to PBC.

\section{Molecular Mimicry of PDC-E2 and Cross Reactivity}

Two triggers, infections and xenobiotics, have been extensively investigated with regard to their role in molecular mimicry. Central to molecular mimicry is the ability of microorganisms that contain immunogenic epitopes (similar to self-antigens) to trigger a cross-species immune response. ${ }^{46}$ Xenobiotics are chemicals that can generate a loss of tolerance to self-proteins, usually as a result of changed immunogenicity through alteration of or complexing to either self-proteins or nonself-proteins. ${ }^{47,48}$

\section{Molecular Mimicry}

In 1964, the term "molecular mimicry" was coined by Damian, who suggested that select antigenic determinants of microorganisms may resemble host epitopes. ${ }^{49}$ Numerous specific infectious agents, mainly bacteria (both gram negative and positive), and viruses (herpes simplex viral, ${ }^{50}$ mouse mammary tumor virus, ${ }^{51,52}$ and Epstein-Barr virus ${ }^{53}$ ), parasites (trypanosomes and Ascaridiagalli ${ }^{54}$ ), and fungi (Saccharomyces cerevisiae ${ }^{55}$ ), have been implicated in PBC. ${ }^{56}$ The classic example is Escherichia coli and it has been reported that urinary tract infections (UTIs) are frequently observed in PBC. $^{57}$ Sera from PBC patients react with both E. coli and human PDC-E2. We also note that Novosphingobium aromaticivorans, a gram-negative bacterium, contains two proteins that share highly homologous amino-acid sequences with the immunodominant epitope of PDC-E2. Specific antibody reactions to this organism have also been detected in PBC patients, and in fact exhibit up to a 1000-fold stronger response than those against $E$. coli. ${ }^{58}$ In addition, a peptide derived from Pseudomonas aeruginosa has been found to be partially homologous to PDC-E2 ${ }_{159-167}$, which is the HLAA*0201-restricted epitope of PDC-E2 recognized by autoreactive cytotoxic T lymphocytes in PBC (- Table 1). ${ }^{59}$

Autoimmune cholangiopathy, which possesses some similarity to human PBC, has occurred after exposure to bacterial components. Lipopolysaccharide (LPS), a specific component of gram-negative bacterial cell walls, injected into mice either alone or in combination with PDC-E2, induces the appearance of portal lymphocytic infiltration and cholangiocyte degeneration such as that seen in human PBC liver. ${ }^{60}$ Furthermore, lipoteichoic acid (LTA), a gram-positive cell wall component, is also involved in systemic multifocal epithelial inflammation in chronic colitis-harboring $\operatorname{TCR} \alpha(-/-) \operatorname{xAIM}(-/-)$ mice. ${ }^{61}$ Serum levels of LTA-specific IgA are also significantly higher in $\mathrm{PBC}$ than in normal controls. ${ }^{62}$ Unmethylated $\mathrm{CpG}$ motifs from bacterial DNA triggers a PDC-specific Th1 response in peripheral blood mononuclear cells (PBMCs) from mice immunized with PDC. ${ }^{63}$

Most studies supporting the role of infectious agents in the pathogenesis of $\mathrm{PBC}$ are based on linear or conformational mimicry between microbial proteins and human mitochondrial antigens. Shared sequences between human and microbial proteins can disrupt immune tolerance by inducing crossreactive antibodies or effector $\mathrm{T}$ cells and/or by promoting epitope spreading. ${ }^{64}$ However, controversy surrounding the concept of infectious agents and their components in the etiology of PBC still exists. ${ }^{65,66}$ 
Table 1 Molecular mimicry and neoantigens to PDC-E2

\begin{tabular}{|c|c|c|c|c|}
\hline & & Epitope mimic or mimotope & Cross reactivity & References \\
\hline \multicolumn{5}{|c|}{ Molecular mimicry } \\
\hline & Escherichia coli & PDC-E2 $212-226$, PDC-E2 $163-176$ & $A b$ and $C D 4$ & 207,245 \\
\hline & Novosphingobium aromaticivorans & PDC-E2 208-237 & $A b$ & 84,246 \\
\hline & Helicobacter pylori & PDC-E2 212-226 & Only in mouse models & 247,248 \\
\hline & Pseudomonas aeruginosa & PDC-E2 159-167 & CD8 TCR & 59 \\
\hline & Haemophilus influenzae & PDC-E2 212-226 & $\mathrm{Ab}$ & 245 \\
\hline & Lactobacillus delbrueckii & PDC-E2 212-226 & $A b$ & 249 \\
\hline & Mycoplasma pneumoniae & PDC & $\mathrm{Ab}$ & 250 \\
\hline & Mycobacterium gordonae & PDC-E2 212-226 & $A b$ & 251 \\
\hline & Borrelia burgdorferi & PDC-E2 208-235 & $\mathrm{Ab}$ & 252 \\
\hline \multicolumn{5}{|l|}{ Xenobiotics } \\
\hline & Lipoic acid moiety replacement & Lipoic acid mimics & AMA & 47 \\
\hline & 6-bromohexanoate & $\begin{array}{l}\text { 12-aa replacement within } \\
\text { lipoic acid moiety }\end{array}$ & AMA & 68 \\
\hline & 2-octynoic acid & PDC-E2 & AMA & 71 \\
\hline & $\begin{array}{l}\text { Structure-activity } \\
\text { relationship (QSAR) analysis }\end{array}$ & Lipoic acid mimics & AMA & 70 \\
\hline
\end{tabular}

\section{Xenobiotics}

Self- or nonself-proteins can be modified by chemical compounds (i.e., xenobiotics) causing a change in molecular structure that enhances immunogenicity. Xenobiotics are important in $\mathrm{PBC}$ because many environmental chemicals are metabolized primarily in the liver and during metabolism, may form reactive metabolites that can modify cellular proteins to form neoantigens. Sufficient data exist supporting the hypothesis that xenobiotic-induced and/or oxidative modification of mitochondrial autoantigens is a critical step leading to loss of tolerance for $\mathrm{PBC}$ patients. ${ }^{67}$ As previously noted, lipoic acid is a critical component of the PDC-E2 epitope. Moreover, lipoic acid, at the exterior of the PDC-E2 protein complex, is accessible to chemical modification.

In 2001, Gershwin and his colleagues replaced the lipoic acid moiety with synthetic structures designed to mimic a xenobiotically modified lipoyl hapten and subsequently quantified the reactivity of these structures with sera from PBC patients. The data demonstrate that AMAs from seropositive patients with $\mathrm{PBC}$, but not controls, reacted against three of 18 organically modified autoepitopes significantly better than to the native domain, ${ }^{47}$ suggesting an organic compound may modify a self-protein and serve as a mimotope.

In 2003, the Gershwin laboratory replaced the lipoic acid moiety of PDC-E2 with a collection of synthetic structures designed to mimic a xenobiotically modified lipoyl hapten on a 12-aa peptide, leading to significantly higher reactivity with AMA. Based on these data, they immunized rabbits with the xenobiotic, 6-bromohexanoate, bovine serum albumin conjugate, and induced AMA production without requirement for the peptide backbone of PDC-E2. ${ }^{68}$ These autoantibodies disappeared when the stimulus was discontinued. In 2007, the same group reported that oxidative stress-induced liver damage leads to a transiently higher frequency of AMA induction, especially in subjects with acetaminophen (APAP) poisoning. ${ }^{69}$

In 2011,quantitative structure-activity relationship (QSAR) analysis was performed on a focused panel of lipoic acid mimics in which the lipoyl disulfide bond was modified. ${ }^{70} 6,8$-bis(acetylthio)octanoic acid (SAc), 8-(acetylthio) octanoic acid (OASAc), and 6,8- bis(propionylthio)octanoic acid (SCOEt) were highly reactive to sera from AMA-positive $\mathrm{PBC}$ patients, at levels even higher than the reactivity against lipoic-acid-conjugated PDC-E2 peptide. Furthermore, two of these compounds (6-bromohexanoate and 2-octynoic acid ${ }^{71}$ ) were capable of inducing AMA and PBC-like liver lesions in guinea pigs ${ }^{72}$ and NOD. $1101^{73}$ or C57BL/ $6{ }^{74}$ mice, respectively. These models illustrate breakdown of tolerance in the absence of exposure to PDC-E2.

Interestingly, 2-octynoic acid is found in several cosmetic products including nail polish; their frequent use among women may contribute to the female predominance of PBC. $^{75,76}$

\section{Apoptosis}

The clearance of apoptotic cells is normally associated with an anti-inflammatory response; this process plays an important role in tissue homeostasis and immune tolerance. ${ }^{77,78}$ Moreover, increasing evidence suggests that failure in clearance of apoptotic cell debris is linked to the breakdown of tolerance and the development of autoimmunity. ${ }^{79-81}$ Apoptosis of biliary epithelial cells (BECs) has been proposed as a potential source of neoantigens that are responsible for activating autoreactive lymphocytes. ${ }^{82}$ Autophagy, the catabolic process 
that leads to cell destruction and the clearance of the resultant cellular debris may also play a significant role in autoimmune diseases. ${ }^{83}$

Mitochondrial antigens are ubiquitously expressed in all nucleated cells, and are phylogenetically highly conserved. ${ }^{84}$ During spontaneous or induced apoptosis, almost all cell types express mitochondrial antigens on the intact plasma membrane and within apoptotic blebs. The apoptotic cells acquire the ability to initiate an autoimmune response by presentation of 2-OADC-derived autoantigens. ${ }^{85}$ In most cell types, the release of lysine-lipoylated sequences from mitochondria during apoptosis leads to oxidation by glutathiones. ${ }^{86}$ The oxidated forms are not immunogenic and are not recognized by serum AMA because glutathionylation masks autoantibody recognition. ${ }^{87}$ Cholangiocytes fail to covalently link glutathione to lysine-lipoyl groups during apoptosis and immunogenicity is retained. The intact PDCE2 in apoptotic fragments can then be taken up by local antigen-presenting cells and transferred to regional lymph nodes for priming of cognate T cells. Lleo and colleagues first reported the presence of PDC-E2 in the blebs of human intrahepatic bile duct cells that were undergoing apoptosis. ${ }^{77}$ Autoantigens found in apoptotic blebs (apotopes) were subsequently taken up by macrophages. ${ }^{88}$ Further study showed that addition of serum AMA to a coculture of macrophages and apotopes led to a significant increase in proinflammatory cytokine secretion. However, the blocking of CD16 mediated complement receptor 3 (CR3) signaling, possibly resulting from the serum anti-CD16 IgM autoantibodies found in PBC, may be related to the delayed clearance of apoptotic BECs by macrophages. ${ }^{89}$
The unique characteristics of BECs during apoptosis might constitute the pathogenic link between the ubiquitous distribution and high degree of conservation across species of the AMA autoantigen and the organ specificity of PBC pathology. ${ }^{85}$

\section{Genetics and Autoimmunity in PBC}

There is a broadly accepted paradigm that genetic susceptibility results in a breakdown in immunological tolerance that may enhance the effect of autoantigens and the degree of an abnormal immune response. Specifically, the role of genetic factors in conferring $\mathrm{PBC}$ susceptibility has been widely demonstrated ( - Fig. 4 ). The relative risk of a family member of a first-degree relative of $\mathrm{PBC}$ patients is 50 - to 100 -fold higher than the general population. ${ }^{90}$ By evaluating the concordance of PBC in a genetically defined population of twin sets (including monozygotic and dizygotic twins), genetic susceptibility was further confirmed. ${ }^{91,92}$ In addition, the significant female preponderance is well known and the median odds ratio in case studies corresponds to a female predominance of up to $9: 1$ to $10: 1$, among the highest described in autoimmune diseases.

\section{Human Leukocyte Antigen}

The major histocompatibility complex (MHC) is located on the short arm of chromosome 6 and harbors genes encoding molecules involved in antigen presentation, and is therefore involved in distinguishing self from non-self. The MHC complex is characterized by a cluster of genes related by sequence homology and/or function: the human leukocyte antigen

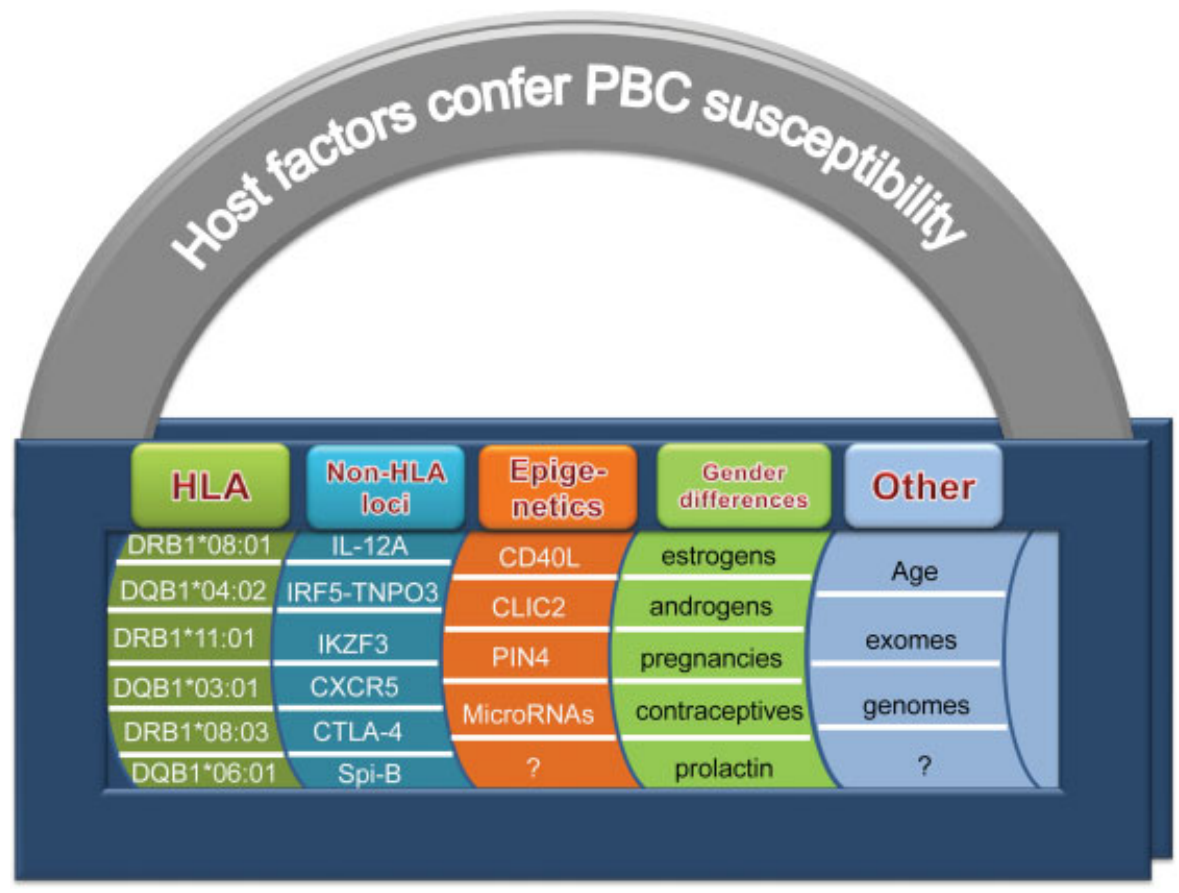

Fig. 4 Genetic factors that confer primary biliary cirrhosis (PBC) susceptibility. The relationship between genetic susceptibility and the breach of tolerance in PBC is complex, involving human leukocyte antigens (HLA), nonhuman leukocyte antigens, antigen risk loci, epigenetics, and sexassociated factors. 
(HLA) class I and HLA class II genes encoding proteins involved in antigen presentation. HLA class III genes encode several other immune proteins, such as tumor necrosis factor- $\alpha$ (TNF$\alpha) .{ }^{93}$ Unlike other autoimmune diseases, there are only weak and regional associations between PBC and HLA molecules. ${ }^{90,94-96}$ In HLA candidate gene studies based on populations of European origin, $\mathrm{PBC}$ is associated with the risk haplotypes, DRB1*08:01-DQA1*04:01-DQB1*04:02 and DRB1 ${ }^{*} 04: 04-D Q B 1{ }^{*} 03: 02 .{ }^{97,98}$ Primary biliary cirrhosis is also associated with the protective haplotypes DRB1*11:01$\mathrm{DQA}^{*}$ 05:01-DQB1*03:01 and DRB1*15:01-DRA1*01:02DQB1*06: 02 . In Japan, DRB1*08:03-DQB1*06:01 and DRB1*04:05-DQB1*04:01 have been identified as risk haplotypes, whereas DRB1*13:02-DQB1*06:04, DRB1*11:01DQB1 ${ }^{*} 03: 01$, and DRB1 ${ }^{*} 15: 01$ act as protective haplotypes. ${ }^{99}$ In a study by Invernizzi et al, conditional analysis showed that these haplotype associations in Italians are most likely driven by the respective DRB1 alleles, the risk alleles DRB1*08 and DRB $1 * 14$, and the protective allele DRB $1 * 11 .{ }^{100}$

No consistent and reproducible associations have been detected between specific DRB1 alleles and clinical features of the disease. In Chinese PBC patients, significant association exists between HLA-DRB1*08:03, DQ2, and DQB1*06:01 alleles and PBC. DRB1*08:03-DQB1*06:01 and DRB1*07:01DQB1*02:02 haplotypes were also associated with $\mathrm{PBC}$ susceptibility. On the other hand, DRB ${ }^{*} 03: 01$ alleles and the DRB1*12:02-DQB1 ${ }^{*}$ 03:01 haplotype were significantly decreased in Chinese PBC patients compared with controls. ${ }^{101}$

\section{Genome-Wide Association Studies}

Genome-wide association study (GWAS) analysis demonstrates that there is less of a difference in the intensity of risk association with $\mathrm{PBC}$ between HLA and non-HLA loci. This finding suggests that although HLA is a very important contributor of risk, the non-HLA loci, as a group, are at least equally important. So far, 27 genome-wide significant nonHLA risk loci for $\mathrm{PBC}$ have been identified, ${ }^{102}$ including 2q32 (STAT1, STAT4), 3q25 (IL12A, SCHIP1), 7q32 (IRF5, TNPO3), 11q23(CXCR5),12p13 (TNFRSF1A, LTBR), 16p13.13 (SOCS1, CLEC16A), 17q12 (IKZF3) and 19q13.3 (SPIB). ${ }^{98,103}$ Risk loci for $\mathrm{PBC}$ appear to be enriched for gene products involved in innate or adaptive immune responses, consistent with an autoimmune component to pathogenesis. Genome-wide association studies now play a significant role in evaluating a genetic role in many autoimmune hepatic diseases. ${ }^{102}$

In 2009, Hirschfield et al identified three susceptibility loci, HLA, IL12A, and IL12RB2, and their observations were confirmed by other GWAS studies. ${ }^{104}$ IL-12,acting as a T-cell stimulating factor that is involved in the differentiation of naive $\mathrm{T}$ cells into Th1 cells, has been previously implicated in autoimmunity and is important for the development of antigen-specific (PDC-E2) autoreactive T cells in PBC. ${ }^{105}$ IL12 is also involved in the activity of natural killer (NK) cells and its cytotoxic activity. In addition, the binding of IL-12 to its receptor is thought to modulate autoimmune responses by evoking IFN- $\gamma$ production, which may in turn alter IL-23driven induction of IL-17-producing Th17 lymphocytes.
Moreover, signals from IL-12R are mediated by TYK2 and STAT4, and negatively regulated by SOCS1. ${ }^{106,107}$

IRF5-TNPO3 (encoding interferon regulatory factor 5 and transportin 3) plays a key role in the innate immune response as part of the Toll-like receptor (TLR) signaling pathway and mediates apoptosis induced by TNF related apoptosis-induced ligand. ${ }^{108}$ IRF5 also contributes to the development of dendritic cells, and promotes inflammatory macrophage polarization and Th1-Th17 responses ${ }^{109}$

CXCR5 (Chemokine (C-X-C Motif) Receptor 5), acting as a multipass membrane protein, is mainly expressed in mature B cells and follicular helper-T cells ( $\mathrm{Tfh}$ ). Expression of CXCR5 affects the migration of $B$ cells into splenic follicles, and may have a regulatory role in B-cell differentiation. Moreover, CXCR5 also affects the function of Tfh cells, which have been reported to play an important role in multiple autoimmune diseases. $^{110}$

The transcription factor IKZF3 gene encodes IKAROS family zinc finger 3 (also known as Aiolos) and plays a critical regulation role in B-cell differentiation, proliferation, and maturation. It also controls apoptosis of $\mathrm{T}$ and $\mathrm{B}$ cells in an IL-2-dependent way, and has been implicated in the pathogenesis of autoimmunity. ${ }^{111} \mathrm{Spi}-\mathrm{B}$ (Spi-B transcription factor [Spi-1/PU.1 related]), a member of the ETS transcription factor family, is an important mediator of both early T-cell lineage differentiation and B-cell receptor signaling. Spi-B also induces the development of plasmacytoid dendritic cells and NK cells.

Other new candidate genes associated with disease at GWAS thresholds include SIAE, TNFSF15, POU2AF1, CTLA-4, IL-1, IL-10, vitamin D receptor (VDR), DENND1B, CD80, IL7R, CLEC16A, PTPN22, and NFKB1, ${ }^{112-118}$ all of which play compelling roles in the development of autoimmunity that require further confirmation or investigation.

\section{Epigenetics}

Epigenetics is defined as stable and heritable patterns of gene expression that do not involve any alterations to the original DNA sequence. There are four known types of epigenetic mechanisms: (1) methylation of DNA on certain cytosine residues that generally silences genes, (2) posttranslational modifications of histone tails of nucleosomes (acetylation, methylation, ubiquitination, etc.) that may either render genes active or inactive depending on the histone modified and the nature of the modification, (3) active remodeling of chromatin by protein machines called remodeling complexes that can also either enhance or suppress, and (4) the silencing of gene expression by small noncoding RNA transcripts. ${ }^{119}$ The lack of concordance in monozygotic twins in autoimmune diseases strongly suggests that besides environmental factors, epigenetic factors may also be important in determining the susceptibility to autoimmunity. ${ }^{9,120,121}$ The relationship between epigenetics and the pathogenesis of autoimmune diseases, including PBC, has been described extensively. ${ }^{91,122-125}$

The interaction of CD40 and CD40L plays a key role in CD4+ T cell priming, B-cell terminal maturation, and immunoglobulin class-switch recombination. No gene mutations 
were detected in CDNA of CD40L from PBC patients by RTPCR-SSCP technique. ${ }^{126}$ Lleo et al has demonstrated significantly lower levels of DNA methylation of the CD40L promoter in CD4 $+\mathrm{T}$ cells from PBC patients, as compared with controls, and this decreased methylation inversely correlated with levels of serum IgM in PBC patients. ${ }^{127}$

The reason for female predominance is unclear, although multiple theories have been proposed. ${ }^{128-138}$ Because the female has two $\mathrm{X}$ chromosomes, one is silenced to varying degrees in a process known as $X$-chromosome inactivation $(\mathrm{XCI})$ or lyonization. Most genes on the inactive $\mathrm{X}$ chromosome are silenced by promoter methylation during X-chromosome inactivation (XCI). ${ }^{139}$ Two genes (CLIC2 and PIN4) were identified as consistently downregulated in an effected cohort of monozygotic twin sets discordant and concordant for PBC. Both CLIC2 and PIN4 demonstrated partial and variable methylation of $\mathrm{CpG}$, but the possible mechanisms by which epigenetic factors influence PBC onset are likely much more complex than a simple X-linking of candidate genes. ${ }^{120,140-142}$

MicroRNAs play a vital role in the regulation of various aspects of immune function and in the development of autoimmune disease. In 2009, it was shown that PBC is associated with altered expression of 35 hepatic microRNAs. ${ }^{143}$ Subsequently, 17 microRNAs differentially expressed in PBMCs from PBC patients were also identified. ${ }^{144}$ Other microRNAs, such as miR-506, ${ }^{145}$ miR-let-7b, miR-505-3p, and miR-197-3p have also been reported to be associated with PBC. ${ }^{146,147}$ However, the precise mechanisms related to the role of microRNA in the maintenance of the breach of immune tolerance in $\mathrm{PBC}$ have yet to be elucidated.

Finally, a considerable number of sex-related genes appear crucial in the maintenance of physiological sex hormone

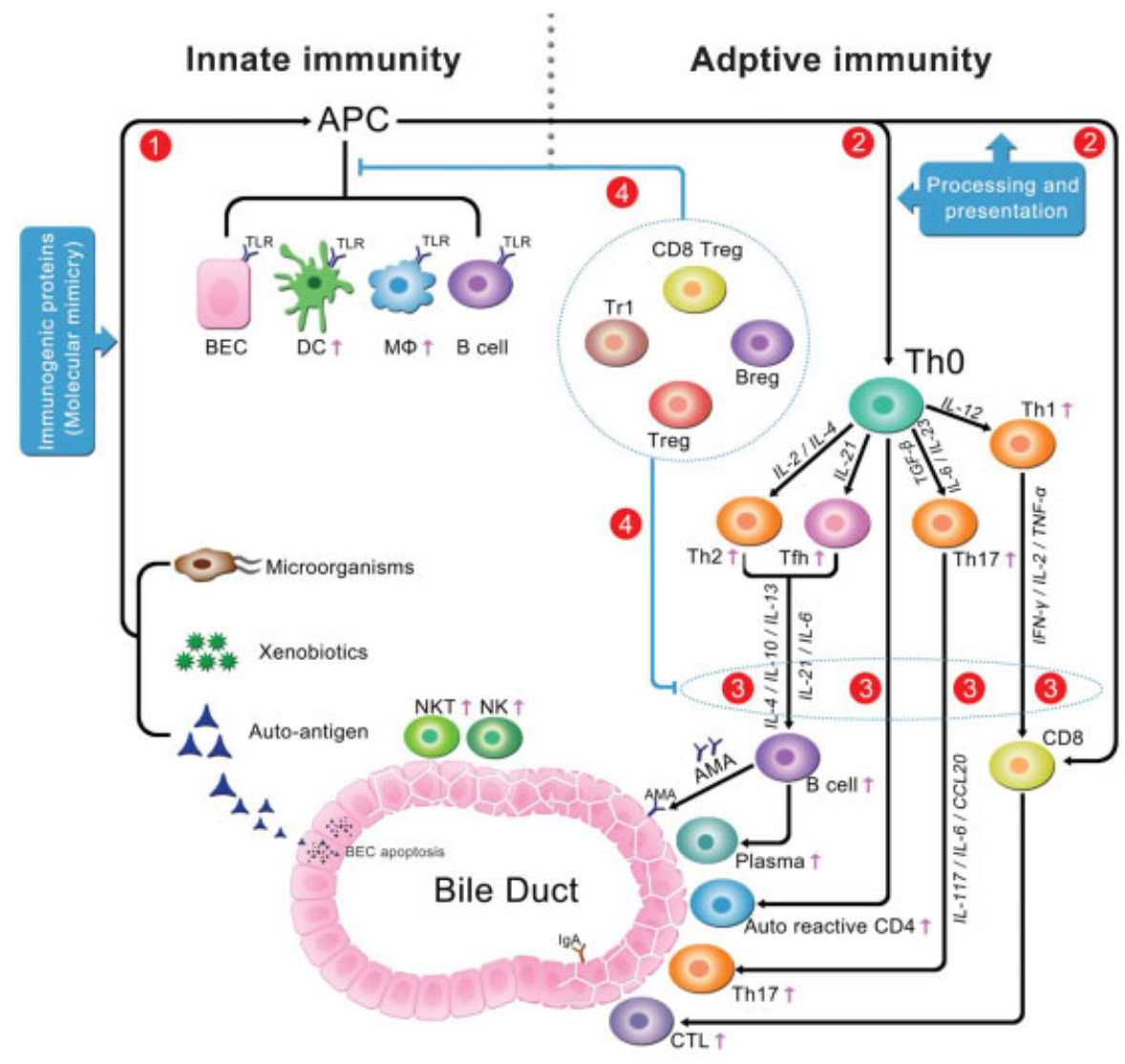

Immune Tolerance

\section{Break Tolerance}

Fig. 5 Innate and adaptive immunity in primary biliary cirrhosis (PBC) patients. (1) Microorganism proteins, xenobiotics, and apoptosis of biliary epithelial cells (BEC) can be recognized and endocytosed by antigen-presenting cells (APCs), which subsequently activate innate immune cells such as Toll-like receptors (TLRs), DCs, macrophages, natural killer (NK) and natural killer T (NKT) cells, and others. (2) After being processed by APCs, some T-cell immunogenic peptides were generated and presented to uncommitted T helper (Th0) lymphocytes and CD8 T cells. (3) Activated Th0 cells then differentiate into Th1, Th2, Tfh, and Th17 cells. Furthermore, Th1 cells secrete cytokines such as interleukin-2 (IL-2) and interferon- $\gamma$, which stimulate development of cytotoxic T lymphocytes (CTL).Th2 cells or Tfh cells secrete IL-4, IL-10, IL-13, or IL-21, and may stimulate autoantibody (e.g., AMA) production by B lymphocytes. Finally, CTL (autoreactive CD8+ T), B lymphocytes, Th17, autoreactive CD4 + T, NK, and NKT infiltrate and gather around the small bile duct, and participate in the development of autoimmunity. (4) Simultaneously, the number and function of immunosuppressive cells (Treg, Breg, Tr1, and CD8 Treg) decrease significantly, which indirectly promotes overactivation of immune responsiveness. Throughout the process, the balance between immune tolerance and break tolerance is a constantly changing process, which finally leads to the breach of tolerance in PBC. 
levels. Often, these genes have a pleotropic function in immune system balance. ${ }^{148}$ Sex-associated hormones, such as estrogens, androgens and prolactin, which not only differ between males and females but also can vary according to age, can be central to the T helper $1 / \mathrm{T}$ helper 2 balance. They may therefore play a significant role in determining an appropriate or inappropriate inflammatory response and thus play a role in the balance between immune tolerance and autoimmunity. ${ }^{149}$ Invernizzi et al ${ }^{150}$ first determined a significantly higher frequency of monosomy of the $\mathrm{X}$ chromosome in peripheral leukocytes (particularly T and B cells) in female PBC subjects as compared with age-matched female controls. Moreover, several sex-related factors (pregnancies, ${ }^{151}$ contraceptives, estrogen-replacement treatments, ${ }^{75}$ and recurrent vaginitis ${ }^{152}$ ) appear to increase the risk of developing PBC. The availability of high-throughput efforts to sequence exomes and genomes and the advent of deep-sequencing should advance these data.

\section{Innate and Adaptive Immunity}

Defects in immune regulation that govern components of both innate and adaptive immunity contribute to the abnormal perpetuation of the immune response (-Fig. 5; - Table 2). Innate immune cells physiologically resident in the liver constantly provide a defense against pathogens while maintaining tolerance to food antigens and commensal bacteria. The evidence for a role of innate immunity in PBC includes the following immunological features: presence of granulomatous inflammation, elevated levels of polyclonal IgM, hyperresponsiveness to $\mathrm{CpG}$, increased levels of $\mathrm{NK}$ cells, and aberrant cytokine responses. ${ }^{153,154}$

\section{Toll-Like Receptors}

Thirteen Toll-like receptors (TLRs) have been described in mammals of which 10 are found in humans. ${ }^{155}$ Toll-like receptors are part of a system of pattern-recognition

Table 2 Innate and adaptive immune in patients with primary biliary cirrhosis

\begin{tabular}{|c|c|c|}
\hline Immune type & Function & Reference \\
\hline \multicolumn{3}{|c|}{ Innate immunity } \\
\hline TLR & TLR signaling; contributes to the breach of tolerance & 154,157 \\
\hline DC & $\begin{array}{l}\uparrow \text { Number (peripheral and intrahepatic) } \uparrow \text { Function } \\
\text { (presenting and cross presenting) }\end{array}$ & $163,164,166$ \\
\hline Macrophage & $\uparrow$ Hypersecretion of proinflammatory cytokines & 168,253 \\
\hline BEC & $\begin{array}{l}\text { Act as antigen presenting cells; defense against } \\
\text { pathogenesis; induces IgA-related damage }\end{array}$ & $173,175,180$ \\
\hline NK & $\begin{array}{l}\uparrow \text { Number (peripheral and intrahepatic) } \uparrow \text { Function } \\
\text { (cytotoxic activity) }\end{array}$ & 184,185 \\
\hline NKT & $\begin{array}{l}\uparrow \text { Number (peripheral and intrahepatic) } \\
\uparrow \text { Function(cytotoxic activity, perforin expression) } \\
\uparrow \text { Lymphoid cell infiltration }\end{array}$ & 187,188 \\
\hline \multicolumn{3}{|c|}{ Adaptive immunity-Cellular immunity } \\
\hline CD4 & $\begin{array}{l}\uparrow \uparrow \text { Autoreactive CD4 T cells (100- to150-fold) } \\
\uparrow \text { Ratio of Th1/Th2 }\end{array}$ & $190,191,203$ \\
\hline Th17 & $\uparrow$ Number (intrahepatic) $\uparrow I L-17$ secretion & $192-194$ \\
\hline Treg & $\begin{array}{l}\downarrow \text { Number (peripheral and intrahepatic) } \\
\downarrow \text { Function (maintenance self-tolerance) }\end{array}$ & 195,196 \\
\hline Tfh & $\begin{array}{l}\uparrow \text { Number (peripheral and intrahepatic) } \\
\uparrow \text { Function (provides help to B cells) }\end{array}$ & \\
\hline CD8 & $\begin{array}{l}\uparrow \text { Autoreactive CD8 T cells (10-fold) } \\
\uparrow \text { Function (cytotoxic activity) }\end{array}$ & 59,208 \\
\hline \multicolumn{3}{|c|}{ - Humoral immunity } \\
\hline Antibodies & $\begin{array}{l}\text { Indicates a breach of immune tolerance } \\
\text { (AMA, AMA-IgA, ANA, anti-Gp120 and anti-Sp100) }\end{array}$ & 211,212 \\
\hline B cells & $\begin{array}{l}\uparrow \text { Number (peripheral and intrahepatic) } \\
\uparrow \text { Intrahepatic CD38+ plasmablast } \\
\uparrow \text { Function (promote antibody production) } \\
\text { Suppressive B cells exist (Breg) }\end{array}$ & $38,214,215,254$ \\
\hline
\end{tabular}

Abbreviations: AMA, antimitochondrial antibody; ANA, antinuclear antibody; BEC, biliary epithelial cell; DC, dendritic cell; IgA, immunoglobulin A; NK, natural killer; NKT, natural killer T; TLR, Toll-like receptor. 
receptors (PRRs) that act by recognizing unique, highly conserved structural components of bacteria, fungi, viruses called pathogen-associated molecular patterns (PAMPS), as well as damage-associated molecular patterns (DAMPs). The binding of PAMPs or DAMPS to TLRs leads to signaling pathways that activate and propagate innate and adaptive inflammatory responses. ${ }^{156}$

The expression of TLRs is normally regulated by a negative signaling pathway in the liver, which prevents inappropriate activation of inflammation. Peripheral blood mononuclear cells in PBC patients produce higher amounts of inflammatory cytokines in response to the ligands of TLR2, TLR3, TLR4, TLR5, and TLR9 than PBMCs in healthy subjects. ${ }^{157}$ In PBC patients, peripheral $B$ cells exposed to $\mathrm{CPG}$ motifs express increased amounts of TRL9 and CD86, which enhance their production of intracellular IgM and AMA. ${ }^{154,158}$

Furthermore, the cytotoxicity of liver NK cells in PBC patients is more profound than cells in control subjects when incubated with poly I:C and LPS-primed liver macrophages. ${ }^{159}$ These results indicate that patients with PBC exhibit hypersensitivity to TLR signaling.

\section{Antigen-Presenting Cells}

\section{Dendritic Cells}

Dendritic cells (DCs) occupy a unique position at the interface between innate and adaptive immunity, orchestrating a large panel of responses. The presentation of antigens by immature DCs should result in immune tolerance, while activated and mature DCs are capable of priming robust adaptive immune responses. ${ }^{160}$ In 1989, Demetris et al first identified dendritic cells that localize inside the basement membrane between biliary epithelial cells of septal bile ducts in livers of early stage PBC. ${ }^{161}$ Using immunohistochemical methods, Tanimoto et al reported that there exists activated CD83-positive DCs in PBC patients. ${ }^{162}$ In 2001, Akbar et al stimulated peripheral blood T cells from PBC with either PDC alone or DCs plus PDC. They reported that peripheral blood $\mathrm{T}$ cells from $100 \%$ of AMApositive $\mathrm{PBC}$ patients reflected $\mathrm{PDC}$-specific proliferation when cultured with PDC-pulsed DCs. ${ }^{163}$ This finding demonstrated the effectiveness of antigen-pulsed DCs.

In 2002, Kita et al also found that PDC-E2-specific cytotoxic T lymphocytes (CTLs) could also be generated by pulsing DCs with full-length recombinant PDC-E2 protein, which indicated that CTL activation could be augmented by immune complexes cross presented by dendritic cells. ${ }^{164}$ Hiasa et al analyzed the phenotypes of DC1 and DC2 from patients with primary biliary cirrhosis. ${ }^{165}$ A phenotype of DC2 with reduced expression of HLA D2 and CD123 in PBC may have relevance to the breakdown of tolerance to self-antigen. In addition, Langerhans cells (LCs) existing around or within biliary epithelial layers are important as periductal antigen-presenting cells in PBC. The migration of LCs into bile ducts is closely associated with the periductal cytokine milieu in patients with PBC. ${ }^{166}$

\section{Monocytes}

Monocytes have also been implicated in the pathogenesis of PBC and other autoimmune diseases. ${ }^{167}$ Peripheral-blood monocytes in PBC are more sensitive to infectious stimuli, which lead to hypersecretion of proinflammatory cytokines. The expression of TLR4 in circulating monocytes increased significantly after stimulation with lipopolysaccharide (LPS) in PBC patients, and circulating monocytes produce higher proinflammatory cytokines, including IL-1 $\beta$, IL-6, IL-8, and TNF- $\alpha^{169}$, that can amplify adaptive T-cell-mediated immune responses against pathogens. At the same time, the level of RP105, which is involved in the negative regulation of TLR4 signaling, is decreased in PBC monocytes. ${ }^{168}$ In the liver of PBC patients, TLR3 is highly expressed on macrophages surrounding the portal tract and on hepatocytes, and these macrophages produce type-I interferon through TLR-3 signaling. ${ }^{169}$ The complexity of the immune response is illustrated by the fact that the proinflammatory cytokine IL- 6 has been found to play a role in activation of IL-10 producing $\operatorname{Tr} 1$ cells in suppressing autoimmune tissue inflammation. ${ }^{170,171}$

\section{Biliary Epithelial Cells}

Biliary epithelial cells (BECs) are not just innocent bystanders in the pathophysiology of PBC. ${ }^{172}$ First, unlike other epithelial cells, BECs act as antigen-presenting cells that express HLA class II ${ }^{173,174}$ and costimulatory molecules, such as CD80 and CD86. ${ }^{175,176}$ After phagocytosing and processing the apoptotic BECs, BECs present novel mitochondrial self-peptides in conjunction with HLA class II. ${ }^{80,176,177}$ Finally, autoreactive T cells against 2-OADC infiltrate into the liver, ${ }^{178}$ and gather around small bile ducts. This was observed in PBC irrespective of their serum AMA status. ${ }^{179}$ These data support the notion that phagocytosis of apoptotic cells by nonprofessional phagocytes may contribute to the tissue specificity of autoimmune diseases. Biliary epithelial cells also contribute to the defense mechanisms against infectious agents by recognition of PAMPs via specific membrane TLRs, resulting in the generation of chemokines that activate both the innate and adaptive immunity systems. Biliary epithelial cells are unique in secreting immunoglobulins A of the secretory type ( $\operatorname{sg} A$ ) through transcytosis in the biliary lumen, which may constitute organ-specific immune-mediated injury. ${ }^{180,181}$

\section{Natural Killer Cells}

Natural killer cells are mainly involved in defense against infections and tumors, but also link innate with adaptive immunity. Several studies indicate that aberrancies in NKcell-mediated immune homeostasis can lead to the onset of autoimmune diseases. ${ }^{182}$ In 2001, Panasiuk et al first reported the increase of NK cell numbers in the peripheral blood of PBC patients. ${ }^{183}$ The finding has been confirmed by Chuang and his colleagues, and it was further demonstrated that NK cells express higher levels of perforin and decreased cytokine production in $\mathrm{PBC}$ patients compared with healthy controls. ${ }^{184}$ At the same time, a higher frequency of CD56dim/ CD16pos hepatic NK cells was present within the liver of PBC patients. Further studies have shown that hepatic NK cells have cytotoxic activity against autologous biliary epithelial cells.

Because NK cells have been reported to express CX3CR1 and CXCR3, it has been hypothesized that the higher 
frequency of cytotoxic NK cells found in the liver of PBC is due to an increased migration of circulating NK cells through mechanisms that involve both CX3CR1 and CXCR3. In a mouse model, there is a marked suppression of AMA and cytokine production from autoreactive T cells after in vivo depletion of NK and natural killer T (NKT) cells. ${ }^{185}$ The increased infiltration of cytotoxic NK cells in the liver may reflect the breakdown of NK cell immune tolerance, but further studies are needed to describe the detailed mechanisms driving the expansion of autoreactive NK cells. ${ }^{186}$

\section{Natural Killer T Cells}

Natural killer $\mathrm{T}$ cells are regulated by self- and nonselfglycolipid antigens that are presented by the antigen-presenting molecule CD1d. This process allows for rapid NKT cell expression of effector cytokines and chemokines, thereby modulating both innate and adaptive immune responses. In PBC, the frequency and absolute number of blood and liver NKT cells are markedly increased compared with healthy controls. Moreover, cytotoxic activity and perforin expression by isolated NKT cells were significantly increased in PBC with increased IL-8 levels and expression of CD128a (IL-8 receptor) on NKT cells. In contrast, the levels of interferon- $\gamma$ (IFN- $\gamma$ ), IL6 , and IL-8 synthesized by NKT cells were significantly decreased in $\mathrm{PBC}$ when compared with controls. ${ }^{187}$ In 2008, Chuang et al generated a CD1d $(-/-)$ dnTGF-nRII mice and reported decreased hepatic lymphoid cell infiltration as well as milder cholangitis than that seen in controls. ${ }^{188}$ CD1d-restricted NKT cells in the liver exhibit increased IFN- $\gamma$ production after exposure to $\alpha$-galactosylceramide. In both $N$. aromaticivorans induced and 2-OA-BSA induced PBC mouse models, NKT cells are involved in disease exacerbations, which include signs of portal inflammation, bile duct destruction, and liver fibrosis. ${ }^{58,189}$

\section{Adaptive Immunity: Cellular Immunity}

\section{Excessive T-Cell Helper Function}

An enhanced ratio of Th1 to Th2 cells is an important factor in the onset of PBC. ${ }^{190,191}$ Th17cells, a subset of CD4 T cells, accumulate around damaged bile ducts in liver and in a mouse model of PBC. ${ }^{192}$ In IL-2R $\alpha(-/$ - ) mice, marked aggregation of IL-17+ cells within portal tracts compared with the periphery has been demonstrated. Interestingly, CD4+ T cells from the livers of normal C57BL/6J mice can secrete higher levels of IL-17 compared with those from spleens, indicating a role of the liver microenvironment in Th17 induction. Finally, Th17 cells involved in the pathogenesis of various autoimmune diseases are also constituents of the periductular infiltrates in human PBC. ${ }^{193,194}$ In recent studies, our preliminary data demonstrated that the frequency of $\mathrm{T}$ follicular helper cells are more highly expressed in PBC patients, and that Tfh accumulates around the damaged bile ducts in liver tissue.

\section{T-Cell Regulation}

CD4 + CD25+ T regulatory cells (Tregs) play an important role in the maintenance of peripheral self-tolerance as well as downregulation of various immune responses. ${ }^{24,25}$ In PBC patients, FoxP3 + Tregs can be identified in the lymphoid infiltrates localized to portal tracts, and significantly lower proportions of circulating CD4 + CD2 $5^{\text {high }}$ Tregs are observed in patients and family members. ${ }^{195}$ In addition, the dnTGFßRII and IL-2R $\alpha$ knockout murine models support a role of Tregs deficiency in loss of immune tolerance. The selective deficiency of the TGF $\beta$ R-signaling pathway exclusively in T lymphocytes accounts for major impairments of peripheral tolerance as Treg cells depend on TGF $\beta$ for their regulatory activity. The result is the triggering of tissuespecific autoreactive effector $\mathrm{T}$ cells. ${ }^{39} \mathrm{~A}$ mouse deficient for IL-2 receptor $\alpha$ (IL-2R $\alpha$ ), which is highly expressed on Tregs, developed 100\% AMA positivity against PDC-E2, 80\% antinuclear antibody (ANA) positivity, and lymphocyte infiltration around the portal tracts associated with cholangiocyte injury. $^{38}$

In 2009, Zhang et al studied Scurfy (Sf) mice, which have a mutation in the gene encoding the Foxp3 transcription factor resulting in a complete abolition of Foxp3+ Tregs. At 3 to 4 weeks of age, $100 \%$ of animals manifested high titers of serum AMA of all isotypes. Furthermore, these mice had moderate to severe lymphocytic infiltrates surrounding portal areas with evidence of biliary duct damage. These data illustrate that lacking normal Treg function is a major predisposing feature for breach of tolerance that leads to PBC. ${ }^{196,197}$

Other regulatory cells, such as CD8 Tregs have also been reported to contribute to a significant phenotypic alteration in PBC patients characterized by increased expression of CD127 and reduced CD39 compared with normal controls. Furthermore, in vitro induction of CD8 Tregs by incubation with IL-10 is significantly reduced in PBC. ${ }^{198}$ The immunomodulatory effects of the tryptophan-catabolizing enzyme indoleamine-2,3-dioxygenase (IDO) have been studied at a cellular level and implicated in the pathogenesis of several complex diseases. Impaired IDO production has been reported and postulated to contribute to the development of disease pathogenesis in PBC patients. ${ }^{199}$

\section{Expansion of the Autoreactive T-Cell Pool}

Under normal circumstances, lymphocytes are scattered throughout the liver parenchyma, as well as in the portal tracts. These lymphocytes belong to several subpopulations. $^{200}$ T-helper $(C D 4+)$ TCR $\alpha \beta+$ and CD8 + T cells are present in portal tracts and around damaged bile ducts, strongly supporting their role in the development of biliary damage. $^{201-207}$ Autoreactive CD4 T cells that specifically target PDC-E2-self-antigen are present in peripheral blood and liver. There is a 100- to150-fold increase in the number of PDC-E2-specific CD4 T cells in the hilar lymph nodes and liver versus peripheral blood in patients with PBC. ${ }^{203}$ The HLA class I restricted epitope for CD8 T cells, namely the 159-167 aa sequence, maps in close vicinity to the epitopes recognized by CD4 T cells as well as by AMA. ${ }^{59}$ Notably, the autoepitope for both CD4 and CD8 T cells overlaps with its B-cell (AMA) epitope, including the inner lipoyl domain. Similar to CD4 autoreactive $\mathrm{T}$ cells, there is a 10 -fold higher frequency of 
Table 3 Novel approaches that may restore immune tolerance in primary biliary cirrhosis

\begin{tabular}{|c|c|c|c|}
\hline & Treatment target & Possible mechanisms & Treatment efficacy \\
\hline \multicolumn{4}{|l|}{ Traditional } \\
\hline UDCA (13-15 mg/kg/d) & Bile acid pool & $\begin{array}{l}\text { Not clear (involving choleresis, } \\
\text { antiapoptosis, anti- } \\
\text { inflammation) }\end{array}$ & About $60 \%$ efficacy \\
\hline \multicolumn{4}{|l|}{ Nonspecific immunosuppression } \\
\hline $\begin{array}{l}\text { Budesonide }^{219,255} \\
\text { Methotrexate and colchicine }^{220} \\
\text { Cyclosporine }^{221} \\
\text { Azathioprine }^{222}\end{array}$ & $\begin{array}{l}\text { Whole activated } \\
\text { immune systems } \\
\text { (autoimmune or } \\
\text { nonspecific } \\
\text { immune) }\end{array}$ & Immunosuppression & $\begin{array}{l}\text { Transitory biochemical } \\
\text { response in some patients, } \\
\text { but with side effects }\end{array}$ \\
\hline \multicolumn{4}{|l|}{ Specific target therapy } \\
\hline Rituximab 216,217 & Total B cells & Depletion B cells & Limited efficacy in patients \\
\hline Ustekinumab ${ }^{226}$ & IL-12/IL-23 & $\begin{array}{l}\text { Block the signal pathway of IL- } \\
12\end{array}$ & In progress (NCT01389973) \\
\hline $\mathrm{NI}-0801$ & CXCR10 (IP-10) & $\begin{array}{l}\text { Inhibits T-cell migration and } \\
\text { inflammation }\end{array}$ & In progress (NCT01430429) \\
\hline $\begin{array}{l}\text { CTLA4/immunoglobulin } \\
230\end{array}$ & CTLA4 & Inhibits T-cell activation & In preclinical studies \\
\hline \multicolumn{4}{|l|}{ Novel therapeutic methods } \\
\hline Mesenchymal stem cells 234,235 & $\begin{array}{l}\text { Whole activated } \\
\text { immune systems } \\
\text { and damaged bile } \\
\text { ducts }\end{array}$ & $\begin{array}{l}\text { Potential immunomodulatory } \\
\text { capacity; tissue regeneration } \\
\text { and repair }\end{array}$ & $\begin{array}{l}\text { Pilot data in PBC patients; } \\
\text { significant benefits in } \\
\text { mouse models }\end{array}$ \\
\hline $\begin{array}{l}\text { Tolerogenic dendritic } \\
\text { cell (tolDCs) vaccine }\end{array}$ & DC & $\begin{array}{l}\text { Induce immune tolerance to } \\
\text { PDC }\end{array}$ & In theoretical stages \\
\hline Oral tolerance $^{238}$ & Immune system & $\begin{array}{l}\text { Induce immune tolerance to } \\
\text { PDC }\end{array}$ & failed \\
\hline SiRNA or microRNA & Key molecular & Restore immune tolerance & In theoretical stages \\
\hline
\end{tabular}

Abbreviations: DC, dendritic cell; IL, interleukin; PBC, primary biliary cirrhosis; PDC, pyruvate dehydrogenase complex; UDCA, ursodeoxycholic acid.

PDC-E2 159-167 specific CD8 T cells in liver compared with blood. Moreover, the frequency of precursor of PDC-E2-specific autoreactive CD8 T cells is significantly higher in earlyrather than late-stage disease. ${ }^{208}$ The autoreactive CD8 T cells in PBC produce IFN- $\gamma$ rather than IL-4/IL-10 cytokines. Autoreactive CD8 $\mathrm{T}$ cells have also been implicated in hepatocyte damage seen in autoimmune hepatitis. ${ }^{209}$

\section{Adaptive Immunity: Humoral Immunity}

A high titer of serum AMA can be detected in up to $95 \%$ of patients with PBC. Antimitochondrial antibodies can be detected even before clinical symptoms or biochemical anomalies. However, most studies have shown that there is no correlation between the level of serum AMA and the severity of PBC. Antimitochondrial antibody positivity alone also does not predict the patient's response to treatment with ursodeoxycholic acid (UDCA). However, AMA-IgA can be detected not only in sera, but also in bile, saliva, and urine of patients with PBC. In one study, AMA-IgA correlates with disease severity. ${ }^{210}$ In addition to AMAs, ANAs are detected in nearly $50 \%$ of patients with $\mathrm{PBC}$, and their presence may be clinically significant. ${ }^{211,212}$
Although B cells are well known for their antibody production, they also participate in antigen presentation, modeling of the spleen architecture, and Th1/Th2 polarization of $T$ cells. $^{213}$ Specific substrates of $\mathrm{B}$ cells can act as negative regulators and facilitate immune tolerance. In the liver of PBC patients, the number of infiltrating $B$ cells is higher than that of PSC patients and normal controls. Moreover, the proportion of CD19 + CD69+ activated B cells is markedly higher in liver than in peripheral blood in $\mathrm{PBC}$, and the number of AMA-producing cells is five-fold greater in liver than in PBMCs. ${ }^{214}$ In 2012, Takahashi et al reported a unique coronal arrangement of CD38 + cells around the intrahepatic bile ducts in PBC, but not in controls; there was an association with AMA titer and an inverse association with serum $\gamma$ glutamyltranspeptidase levels. ${ }^{215}$

In a dnTGF- $\beta$ RII PBC mouse model, anti-CD20 administered every 2 weeks ameliorated autoimmune cholangitis if given early in the disease process. ${ }^{216}$ In PBC, a regimen of two doses of $1000 \mathrm{mg}$ rituximab (mouse-human chimeric antiCD20 monoclonal antibody) separated by 2 weeks was found to be safe, but only marginally effective in some patients, who had an incomplete UDCA response. ${ }^{217}$ In 2-octynoic acid- 
bovine serum albumin (2OA-BSA)-induced mice, treatment with anti-CD20 and anti-CD79 antibodies led to a higher number CD4+ and CD8 + T cells around damaged bile ducts in portal areas, which manifest as more severe cholangitis. ${ }^{218}$ Adoptive transfer of CD19+ cells from dnTGF- $\beta R I I$ mice into recombination activating gene-1 (Rag- 1$)(-/-)$ mice resulted in decreased liver inflammation and bile duct damage. ${ }^{216}$ Together, these findings suggest that there is a subclass of $B$ cells that has a regulatory role by producing IL-10. However, further studies are needed to explore the functions of B cells in PBC.

\section{Novel Approaches to Restore Immune Tolerance in Primary Biliary Cirrhosis}

Currently, UDCA is the only drug approved by the Food and Drug Administration to treat PBC patients. Early treatment with UDCA at a dose of 13 to $15 \mathrm{mg} / \mathrm{kg}$ per day can delay the progression of histological changes, ameliorate long-term morbidity, and prolong life expectancy. Ursodeoxycholic acid acts by increasing the hydrophilic properties of the bile acid pool, producing bicarbonate-rich choleresis, which protects against hepatocellular damage. However, over $40 \%$ of patients have an incomplete response to UDCA, resulting in progressive disease necessitating liver transplantation or ultimately resulting in death from liver-related causes. Therefore, future studies should focus on the development of novel approaches that restore the immune tolerance in PBC (-Table 3).

Unlike other autoimmune diseases, nonspecific immunosuppressive medication is not recommended as a first-line strategy for PBC. But it is sometimes used in patients who fail to respond to UDCA. In 2000, Angulo et al treated PBC patients who had an incomplete response to UDCA therapy with budesonide, a corticosteroid with an extensive first-pass hepatic metabolism. ${ }^{219}$ After 1-year treatment, there was a significant but transitory improvement in serum levels of total bilirubin, and a significant but marginal improvement in serum alkaline phosphatase. The Mayo risk score increased significantly, and there was a significant loss of bone mass of the lumbar spine. In 2010, Kaplan et al treated PBC patients who had not responded fully to UDCA with methotrexate and colchicine. $^{220}$ The result showed that methotrexate and colchicine significantly improved liver enzyme tests and liver histology. Others, like cyclosporine, ${ }^{221}$ azathioprine ${ }^{222}$ were also used to treat PBC patients. However, these nonspecific immunosuppression drugs not only suppressed the underlying autoimmune disease, but also led to global suppression of the immune system. The results of this approach include side effects such as increased risk of infection, carcinogenesis, and osteoporosis. There is a clear need for more specific strategies to restore immune tolerance to the specific autoantigens implicated in disease pathology.

Ideally, autoimmune disease therapies would uniquely target the specific autoreactive lymphocyte populations, while leaving unperturbed the rest of the immune system. Primate or humanized monoclonal antibodies against pan-T cell or B cells as well as leukocyte-specific antigens or soluble receptors have been used extensively in the treatment of autoimmune diseases. ${ }^{223}$ Several antibodies targeting specific cells or signaling pathways have been also applied in $\mathrm{PBC}$ patients.

In $\mathrm{PBC}$ patients, although the role of $\mathrm{B}$ cells in the pathogenesis is not clearly defined, B-cell depletion therapy has been shown to be of potential value. The concept of $B$ cell depletion was first tried in a PBC mice model, Moritoki et al showed that in younger dominant-negative TGF- $\beta$ RII mice aged 4 to 6 weeks, anti-CD20 treatment significantly alleviated liver inflammation and reduced bile duct damage. ${ }^{216}$ Rituximab is a mouse-human chimeric anti-CD20 monoclonal antibody designed for B-cell depletion therapy in humans. It has been approved for the treatment of lymphoma and certain autoimmune diseases such as rheumatoid arthritis. Tsuda et al used rituximab to treat six patients with PBC who had suboptimal biochemical response to UDCA. ${ }^{217}$ After B-cell depletion, they observed a reduction in the number of AMA-producing $B$ cells, AMA titers, serum alkaline phosphatase levels (ALP), and plasma levels of immunoglobulins (IgA, $\operatorname{IgM}$, and $\operatorname{IgG}$ ) at week 24 . As the levels of immunoglobulins, AMA titers and ALP returned to baseline levels at week 36, repeated antiCD20 treatment was suggested to maintain the treatment effect. However, there were two patients who experienced upper respiratory infection and reactivation of varicella zoster after the first infusion. Further clinical studies targeting B cells in PBC patients are warranted. ${ }^{224}$

Interleukin-12 (IL-12) and its receptors have been identified as susceptibility genes for PBC, and play a very important role in the breakdown of immune tolerance, thereby offering another potential therapeutic target. ${ }^{225}$ Ustekinumab, ${ }^{226}$ a human monoclonal antibody directed against IL-12 and IL-23, is involved in immune regulation and has the potential to mediate certain autoimmune diseases such as active psoriasis arthritis. $^{227}$ A phase II clinical trial (NCT01389973) using ustekinumab to treat PBC patients is in progress.

CXCL-10 has been shown to play a role in autoimmunity. ${ }^{228}$ Plasma and portal IFN- $\gamma$-inducible protein-10 (IP-10) levels were found to be increased in $\mathrm{PBC}$ patients compared with controls. $^{229}$ NI-0801, an anti-CXCL10 monoclonal antibody that inhibits T-cell migration and inflammation, is being studied in the treatment of PBC patients in a phase II clinical trial (NCT01430429). Other specific antibody treatments, such as those targeting CTLA4/immunoglobulin, ${ }^{230,231}$ are also in preclinical studies in mouse models, and offer other potential areas of pharmaceutical development in the treatment of $\mathrm{PBC}{ }^{232}$

\section{Mesenchymal Stem Cells: Re-establishing Immune Tolerance}

Mesenchymal stem cells (MSCs) have been used as a therapeutic strategy for tissue regeneration and repair, and their potential immunomodulatory capacity, especially in the induction of immune tolerance, has raised significant clinical interest. Recently, autologous and allogeneic MSCs have been reported to significantly improve symptoms in patients with severe autoimmune diseases, such as Crohn disease, multiple 
sclerosis, refractory systemic lupus erythematosus, and systemic sclerosis. $^{233}$

Mesenchymal stem cells have also been used in mouse models of PBC. In 2011, Wang et al used bone marrow-derived mesenchymal stem cells (BM-MSC) in treatment of polyinosinic-cytidylic acid poly (I:C) induced $\mathrm{C} 57 \mathrm{BL} / 6$ PBC mouse model. ${ }^{234}$ The result showed that after 6 weeks of MSC infusions, serum aminotransferase and autoimmune antibodies declined, and histological examination showed significant amelioration of monocyte infiltration around bile ducts. In addition, allogeneic BM-MSC transplantation markedly increased $\mathrm{CD} 4+$ Foxp3 + regulatory $\mathrm{T}$ cells in peripheral blood as well as lymph nodes. In our pilot studies, ${ }^{235}$ umbilical cord-derived mesenchymal stem cells (UC-MSCs) were administered three times at 4-week intervals to seven PBC patients who were suboptimally treated with UDCA. The patients were followed for a 48-week period. The result of this proof of concept study indicated that MSC treatment in $\mathrm{PBC}$ is safe. Fatigue and pruritus were alleviated in most patients after UC-MSC treatment. There was a significant decrease in serum alkaline phosphatase and $\gamma$-glutamyltransferase levels at the end of the follow-up period as compared with baseline. A larger, randomized controlled cohort study is warranted to confirm the clinical efficacy of UC-MSC transfusion.

\section{Novel Vaccine Therapies}

Tolerogenic dendritic cell (tolDCs) vaccines, an antigen-specific treatment that only targets the autoreactive inflammatory response, has already been proven effective in experimental animal models of various autoimmune disorders as well as with in vitro experiments using ex vivo generated human tolDCs. ${ }^{236}$ A PDC-E2 specific tolDCs is a potential strategy for the treatment of PBC.

Induction of oral tolerance by administration of protein antigens has the potential to induce antigen-specific immunological unresponsiveness (immune tolerance). High doses of orally fed antigen may lead to deletion or anergy of Th cells, whereas low-dose administration leads to induction of transforming growth factor (TGF)- $\beta$-secreting regulatory T cells. ${ }^{237}$ This approach represents a potential means to prevent or treat autoimmune disease. Suzuki et al administered $5 \mathrm{mg}$ PDC in gelatin capsules to six PBC patients for 12 months, but failed to induce oral tolerance. ${ }^{238}$

Since the discovery of the RNAi pathway, there has been an increase in interest in the development of RNAi-based therapeutics for "undruggable" targets. Undruggable targets are those pathogenic molecules that cannot be targeted due to chemical, structural, or accessibility limitations. Using conventional therapy, only $\sim 20 \%$ of molecules are targetable. siRNA therapy has the potential to break this barrier, and has been used in autoimmune mouse models for rheumatoid arthritis and Sjögren (SjS) syndrome to restore immune tolerance. 239,240 Similarly, siRNAs or microRNA targeting special genes might be another potential therapeutic method for the treatment of PBC patients. ${ }^{241,242}$

The concept of a breach of immune tolerance in autoimmune disease may change the way we think about PBC and its treatment. In the future, novel therapeutic approaches based on restoration of immune tolerance will be developed to maintain disease remission with minimal ongoing treatment or a drug-free regimen (such as stem cell therapy) rather than the use of general immunosuppressive agents. ${ }^{243}$

\section{Summary}

In PBC, considerable progress has been made in understanding the basic mechanisms of the breach of tolerance, but our knowledge is still incomplete.

In most autoimmune diseases, the treatment generally involves immunosuppression. In PBC, most immunosuppressive agents have proven to be relatively ineffective. ${ }^{244}$ This indicates that the pathogenesis of $\mathrm{PBC}$ is not simply an overreactive immune system directed against a self-antigen, but more likely involves an imbalance in immune tolerance that is affected by many different factors. The specific role of these factors, which may include those that are involved in innate immunity, and additionally those that are involved in cellular regulation, such as $\mathrm{T}$ regulatory cells, is not completed elucidated.

Primary biliary cirrhosis, being a chronic liver disease, is generally characterized by a slow progression but a highly variable clinical course. The clinical features and natural history of the disease vary greatly between patients, ranging from asymptomatic and slowly progressive to symptomatic and rapidly evolving to decompensated status. However, very little is known about the relationship between the variable clinical course of PBC and its immune tolerance state. Moreover, the exact time point of the breach in immune tolerance is unclear. Whether it occurs in asymptomatic clinical stages when AMA may be detected, or only in liver biopsy stage I and beyond where the disease has progressed to small bile duct damage needs to be further elaborated.

It is unclear where the breach in tolerance in PBC originates. Tolerance is regulated by both innate and adaptive immunity, and $\mathrm{PBC}$ may occur through different mechanisms. This is illustrated by the fact that some PBC patients are AMA positive, while others are AMA negative, but patients lacking AMAs present with similar disease characteristics and progression as AMA-positive patients. The quality of life and life expectancy in responders to UDCA treatment are comparable with the general population. However, the $40 \%$ of patients who are UDCA unresponders exhibit a much more aggressive disease progression that can lead to liver transplantation. The mechanisms that affect UDCA responsiveness may be a combination of genetic factors and environmental exposures.

There are other factors that may also play a role in the breach of immune tolerance in $\mathrm{PBC}$ patients. The majority of the patients are in their sixth decade of life at the time of diagnosis of PBC. Immunosenescence (aging of the immune system), which may result in a decline of $\mathrm{T}$ - and B-cell function, may be accompanied by a loss of ability to differentiate "self" and "foreign" antigens and may contribute to the development of PBC. Finally, further research is needed to decipher the extent of the involvement of various components in the pathogenesis of PBC. Novel approaches that are 
based on an understanding of the detailed mechanisms may then be developed and used to improve treatment efficacy in the future.

\section{References}

1 Kaplan MM, Gershwin ME. Primary biliary cirrhosis. N Engl J Med 2005;353(12):1261-1273

2 Perricone C, Colafrancesco S, Mazor RD, Soriano A, Agmon-Levin $\mathrm{N}$, Shoenfeld Y. Autoimmune/inflammatory syndrome induced by adjuvants (ASIA) 2013: unveiling the pathogenic, clinical and diagnostic aspects. J Autoimmun 2013;47:1-16

3 Selmi C, Leung PS, Sherr DH, et al. Mechanisms of environmental influence on human autoimmunity: a National Institute of Environmental Health Sciences expert panel workshop. J Autoimmun 2012;39(4):272-284

4 Hirschfield GM, Gershwin ME. The immunobiology and pathophysiology of primary biliary cirrhosis. Annu Rev Pathol 2013; 8:303-330

5 Wildner G, Kaufmann U. What causes relapses of autoimmune diseases? The etiological role of autoreactive T cells. Autoimmun Rev 2013;12(11):1070-1075

6 Mackay IR. Autoimmunity since the 1957 clonal selection theory: a little acorn to a large oak. Immunol Cell Biol 2008;86(1):67-71

7 Cohn M, Mitchison NA, Paul WE, Silverstein AM, Talmage DW, Weigert M. Reflections on the clonal-selection theory. Nat Rev Immunol 2007;7(10):823-830

8 Billingham RE, Brent L, Medawar PB. Actively acquired tolerance of foreign cells. Nature 1953;172(4379):603-606

9 Pillai S. Rethinking mechanisms of autoimmune pathogenesis. J Autoimmun 2013;45:97-103

10 Kappler JW, Roehm N, Marrack P. T cell tolerance by clonal elimination in the thymus. Cell 1987;49(2):273-280

11 Kisielow P, Blüthmann H, Staerz UD, Steinmetz M, von Boehmer $\mathrm{H}$. Tolerance in T-cell-receptor transgenic mice involves deletion of nonmature CD4+8+ thymocytes. Nature 1988;333(6175): 742-746

12 Palmer E. Negative selection-clearing out the bad apples from the T-cell repertoire. Nat Rev Immunol 2003;3(5):383-391

13 Starr TK, Jameson SC, Hogquist KA. Positive and negative selection of T cells. Annu Rev Immunol 2003;21:139-176

14 Pugliese A. Central and peripheral autoantigen presentation in immune tolerance. Immunology 2004;111(2):138-146

15 Van Parijs L, Abbas AK. Homeostasis and self-tolerance in the immune system: turning lymphocytes off. Science 1998; 280(5361):243-248

16 Walker LS, Abbas AK. The enemy within: keeping self-reactive T cells at bay in the periphery. Nat Rev Immunol 2002;2(1):11-19

17 Halverson R, Torres RM, Pelanda R. Receptor editing is the main mechanism of $B$ cell tolerance toward membrane antigens. Nat Immunol 2004;5(6):645-650

18 Tiegs SL, Russell DM, Nemazee D. Receptor editing in self-reactive bone marrow B cells. J Exp Med 1993;177(4):1009-1020

19 Eisenberg RA. Secondary receptor editing in the generation of autoimmunity. Autoimmun Rev 2012;11(11):787-789

20 Goodnow CC, Adelstein S, Basten A. The need for central and peripheral tolerance in the B cell repertoire. Science 1990; 248(4961):1373-1379

21 Guerder S, Picarella DE, Linsley PS, Flavell RA. Costimulator B7-1 confers antigen-presenting-cell function to parenchymal tissue and in conjunction with tumor necrosis factor alpha leads to autoimmunity in transgenic mice. Proc Natl Acad Sci U S A 1994; 91(11):5138-5142

22 Weigle WO. Analysis of autoimmunity through experimental models of thyroiditis and allergic encephalomyelitis. Adv Immunol 1980;30:159-273
23 Pan PY, Ozao J, Zhou Z, Chen SH. Advancements in immune tolerance. Adv Drug Deliv Rev 2008;60(2):91-105

24 Sakaguchi S. Naturally arising CD4+ regulatory t cells for immunologic self-tolerance and negative control of immune responses. Annu Rev Immunol 2004;22:531-562

25 Shevach EM. Regulatory T cells in autoimmmunity*. Annu Rev Immunol 2000;18:423-449

26 Askenasy N. Enhanced killing activity of regulatory T cells ameliorates inflammation and autoimmunity. Autoimmun Rev 2013; 12(10):972-975

27 Xiao J, Liu C, Li G, et al. PDCD5 negatively regulates autoimmunity by upregulating FOXP3(+) regulatory $\mathrm{T}$ cells and suppressing Th17 and Th1 responses. J Autoimmun 2013;47:34-44

28 Bogdanos DP, Gao B, Gershwin ME. Liver immunology. Compr Physiol 2013;3(2):567-598

29 Selmi C, Mackay IR, Gershwin ME. The immunological milieu of the liver. Semin Liver Dis 2007;27(2):129-139

30 Invernizzi P. Liver auto-immunology: the paradox of autoimmunity in a tolerogenic organ. J Autoimmun 2013;46:1-6

31 Tiegs G, Lohse AW. Immune tolerance: what is unique about the liver. J Autoimmun 2010;34(1):1-6

32 Gianchecchi E, Delfino DV, Fierabracci A. Recent insights into the role of the PD-1/PD-L1 pathway in immunological tolerance and autoimmunity. Autoimmun Rev 2013;12(11):1091-1100

33 Avrameas S, Selmi C. Natural autoantibodies in the physiology and pathophysiology of the immune system. J Autoimmun 2013; 41:46-49

34 Bailey M, Christoforidou Z, Lewis M. Evolution of immune systems: specificity and autoreactivity. Autoimmun Rev 2013; 12(6):643-647

35 Gershwin ME, Mackay IR, Sturgess A, Coppel RL. Identification and specificity of a cDNA encoding the $70 \mathrm{kd}$ mitochondrial antigen recognized in primary biliary cirrhosis. J Immunol 1987;138(10):3525-3531

36 Selmi C, Mackay IR, Gershwin ME. The autoimmunity of primary biliary cirrhosis and the clonal selection theory. Immunol Cell Biol 2011;89(1):70-80

37 Duarte-Rey C, Bogdanos D, Yang CY, et al. Primary biliary cirrhosis and the nuclear pore complex. Autoimmun Rev 2012;11(12): 898-902

38 Wakabayashi K, Lian ZX, Moritoki Y, et al. IL-2 receptor alpha(-/-) mice and the development of primary biliary cirrhosis. Hepatology 2006;44(5):1240-1249

39 Oertelt S, Lian ZX, Cheng CM, et al. Anti-mitochondrial antibodies and primary biliary cirrhosis in TGF-beta receptor II dominantnegative mice. J Immunol 2006;177(3):1655-1660

40 Irie J, Wu Y, Wicker LS, et al. NOD.c3c4 congenic mice develop autoimmune biliary disease that serologically and pathogenetically models human primary biliary cirrhosis. J Exp Med 2006; 203(5):1209-1219

41 Rose NR, Bona C. Defining criteria for autoimmune diseases (Witebsky's postulates revisited). Immunol Today 1993;14(9): 426-430

42 Anaya JM. Common mechanisms of autoimmune diseases (the autoimmune tautology). Autoimmun Rev 2012;11(11):781-784

43 Reed LJ, Hackert ML. Structure-function relationships in dihydrolipoamide acyltransferases. J Biol Chem 1990;265(16): 8971-8974

44 Meda F, Zuin M, Invernizzi P, Vergani D, Selmi C. Serum autoantibodies: a road map for the clinical hepatologist. Autoimmunity 2008;41(1):27-34

45 Gershwin ME, Ansari AA, Mackay IR, et al. Primary biliary cirrhosis: an orchestrated immune response against epithelial cells. Immunol Rev 2000;174:210-225

46 Bogdanos DP, Smyk DS, Invernizzi P, et al. Infectome: a platform to trace infectious triggers of autoimmunity. Autoimmun Rev 2013; 12(7):726-740 
47 Long SA, Quan C, Van de Water J, et al. Immunoreactivity of organic mimeotopes of the E2 component of pyruvate dehydrogenase: connecting xenobiotics with primary biliary cirrhosis. J Immunol 2001;167(5):2956-2963

48 Long SA, Van de Water J, Gershwin ME. Antimitochondrial antibodies in primary biliary cirrhosis: the role of xenobiotics. Autoimmun Rev 2002;1(1-2):37-42

49 Ehser J, Holdener M, Christen S, et al. Molecular mimicry rather than identity breaks T-cell tolerance in the CYP2D6 mouse model for human autoimmune hepatitis. J Autoimmun 2013;42:39-49

50 Fujiwara K, Yokosuka O. Frequent detection of immunoglobulin $\mathrm{M}$ anti-herpes simplex viral antibody in patients with primary biliary cirrhosis. Hepatology 2012;56(1):395

$51 \mathrm{Xu} \mathrm{L}$, Shen Z, Guo L, et al. Does a betaretrovirus infection trigger primary biliary cirrhosis? Proc Natl Acad Sci U S A 2003;100(14): 8454-8459

52 Selmi C, Ross SR, Ansari AA, et al. Lack of immunological or molecular evidence for a role of mouse mammary tumor retrovirus in primary biliary cirrhosis. Gastroenterology 2004;127(2): 493-501

53 Morshed SA, Nishioka M, Saito I, Komiyama K, Moro I. Increased expression of Epstein-Barr virus in primary biliary cirrhosis patients. Gastroenterol Jpn 1992;27(6):751-758

54 Uzoegwu PN, Baum H, Williamson J. The occurrence and localization in trypanosomes and other endo-parasites of an antigen cross-reacting with mitochondrial antibodies of primary biliary cirrhosis. Comp Biochem Physiol B 1987;88(4):1181-1189

55 Sakly W, Jeddi M, Ghedira I. Anti-Saccharomyces cerevisiae antibodies in primary biliary cirrhosis. Dig Dis Sci 2008;53(7): 1983-1987

56 Selmi C, De Santis M, Cavaciocchi F, Gershwin ME. Infectious agents and xenobiotics in the etiology of primary biliary cirrhosis. Dis Markers 2010;29(6):287-299

57 Varyani FK, West J, Card TR. An increased risk of urinary tract infection precedes development of primary biliary cirrhosis. BMC Gastroenterol 2011;11:95

58 Mattner J, Savage PB, Leung P, et al. Liver autoimmunity triggered by microbial activation of natural killer T cells. Cell Host Microbe 2008;3(5):304-315

59 Kita H, Matsumura S, He XS, et al. Analysis of TCR antagonism and molecular mimicry of an HLA-A0201-restricted CTL epitope in primary biliary cirrhosis. Hepatology 2002;36(4 Pt 1):918-926

60 Ide T, Sata M, Suzuki H, et al. An experimental animal model of primary biliary cirrhosis induced by lipopolysaccharide and pyruvate dehydrogenase. Kurume Med J 1996;43(3):185-188

61 Haruta I, Hashimoto E, Shibata N, Kato Y, Kobayashi M, Shiratori K. Lipoteichoic acid may affect the pathogenesis of PBC-like bile duct damage and might be involved in systemic multifocal epithelial inflammations in chronic colitis-harboring TCRalpha-/-xAIM-/mice. Autoimmunity 2007;40(5):372-379

62 Tarner IH, Fathman CG. Does our current understanding of the molecular basis of immune tolerance predict new therapies for autoimmune disease? Nat Clin Pract Rheumatol 2006;2(9): 491-499

63 Jones DE, Palmer JM, Burt AD, Walker C, Robe AJ, Kirby JA. Bacterial motif DNA as an adjuvant for the breakdown of immune self-tolerance to pyruvate dehydrogenase complex. Hepatology 2002;36(3):679-686

64 Agmon-Levin N, Katz BS, Shoenfeld Y. Infection and primary biliary cirrhosis. Isr Med Assoc J 2009;11(2):112-115

65 Dubel L, Tanaka A, Leung PS, et al. Autoepitope mapping and reactivity of autoantibodies to the dihydrolipoamide dehydrogenase-binding protein (E3BP) and the glycine cleavage proteins in primary biliary cirrhosis. Hepatology 1999;29(4):1013-1018

66 Selmi C, Gershwin ME. The retroviral myth of primary biliary cirrhosis: is this (finally) the end of the story? J Hepatol 2009; 51(2):412-413, author reply 414-415
67 Leung PS, Wang J, Naiyanetr P, et al. Environment and primary biliary cirrhosis: electrophilic drugs and the induction of AMA. J Autoimmun 2013;41:79-86

68 Leung PS, Quan C, Park O, et al. Immunization with a xenobiotic 6bromohexanoate bovine serum albumin conjugate induces antimitochondrial antibodies. J Immunol 2003;170(10):5326-5332

69 Leung PS, Rossaro L, Davis PA, et al Acute Liver Failure Study Group. Antimitochondrial antibodies in acute liver failure: implications for primary biliary cirrhosis. Hepatology 2007;46(5): 1436-1442

70 Naiyanetr P, Butler JD, Meng L, et al. Electrophile-modified lipoic derivatives of PDC-E2 elicits anti-mitochondrial antibody reactivity. J Autoimmun 2011;37(3):209-216

71 Rieger R, Leung PS, Jeddeloh MR, et al. Identification of 2-nonynoic acid, a cosmetic component, as a potential trigger of primary biliary cirrhosis. J Autoimmun 2006;27(1):7-16

72 Leung PS, Park O, Tsuneyama K, et al. Induction of primary biliary cirrhosis in guinea pigs following chemical xenobiotic immunization. J Immunol 2007;179(4):2651-2657

73 Wakabayashi K, Yoshida K, Leung PS, et al. Induction of autoimmune cholangitis in non-obese diabetic (NOD).1101 mice following a chemical xenobiotic immunization. Clin Exp Immunol 2009; 155(3):577-586

74 Wakabayashi K, Lian ZX, Leung PS, et al. Loss of tolerance in C57BL/6 mice to the autoantigen E2 subunit of pyruvate dehydrogenase by a xenobiotic with ensuing biliary ductular disease. Hepatology 2008;48(2):531-540

75 Gershwin ME, Selmi C, Worman HJ, et al; USA PBC Epidemiology Group. Risk factors and comorbidities in primary biliary cirrhosis: a controlled interview-based study of 1032 patients. Hepatology 2005;42(5):1194-1202

76 Prince MI, Ducker SJ, James OF. Case-control studies of risk factors for primary biliary cirrhosis in two United Kingdom populations. Gut 2010;59(4):508-512

77 Lleo A, Selmi C, Invernizzi P, Podda M, Gershwin ME. The consequences of apoptosis in autoimmunity. J Autoimmun 2008; 31(3):257-262

78 Elliott MR, Ravichandran KS. Clearance of apoptotic cells: implications in health and disease. J Cell Biol 2010;189(7): 1059-1070

79 Clancy RM, Neufing PJ, Zheng P, et al. Impaired clearance of apoptotic cardiocytes is linked to anti-SSA/Ro and -SSB/La antibodies in the pathogenesis of congenital heart block. J Clin Invest 2006;116(9):2413-2422

80 Allina J, Hu B, Sullivan DM, et al. T cell targeting and phagocytosis of apoptotic biliary epithelial cells in primary biliary cirrhosis. J Autoimmun 2006;27(4):232-241

81 Lleo A, Invernizzi P, Selmi C, et al. Autophagy: highlighting a novel player in the autoimmunity scenario. J Autoimmun 2007;29(23):61-68

82 Lleo A, Invernizzi P, Mackay IR, Prince H, Zhong RQ, Gershwin ME. Etiopathogenesis of primary biliary cirrhosis. World J Gastroenterol 2008;14(21):3328-3337

83 Gianchecchi E, Delfino DV, Fierabracci A. Recent insights on the putative role of autophagy in autoimmune diseases. Autoimmun Rev 2014;13(3):231-241

84 Padgett KA, Selmi C, Kenny TP, et al. Phylogenetic and immunological definition of four lipoylated proteins from Novosphingobium aromaticivorans, implications for primary biliary cirrhosis. J Autoimmun 2005;24(3):209-219

85 Lleo A, Bowlus CL, Yang GX, et al. Biliary apotopes and antimitochondrial antibodies activate innate immune responses in primary biliary cirrhosis. Hepatology 2010;52(3):987-998

86 Odin JA, Huebert RC, Casciola-Rosen L, LaRusso NF, Rosen A. Bcl-2dependent oxidation of pyruvate dehydrogenase-E2, a primary biliary cirrhosis autoantigen, during apoptosis. J Clin Invest 2001; 108(2):223-232 
87 Sasaki M, Ikeda H, Nakanuma Y. Activation of ATM signaling pathway is involved in oxidative stress-induced expression of mito-inhibitory p21WAF1/Cip1 in chronic non-suppurative destructive cholangitis in primary biliary cirrhosis: an immunohistochemical study. J Autoimmun 2008;31(1):73-78

88 Lleo A, Selmi C, Invernizzi P, et al. Apotopes and the biliary specificity of primary biliary cirrhosis. Hepatology 2009;49(3): 871-879

89 Allina J, Stanca CM, Garber J, et al. Anti-CD16 autoantibodies and delayed phagocytosis of apoptotic cells in primary biliary cirrhosis. J Autoimmun 2008;30(4):238-245

90 Parikh-Patel A, Gold E, Mackay IR, Gershwin ME. The geoepidemiology of primary biliary cirrhosis: contrasts and comparisons with the spectrum of autoimmune diseases. Clin Immunol 1999;91(2):206-218

91 Selmi C, Mayo MJ, Bach N, et al. Primary biliary cirrhosis in monozygotic and dizygotic twins: genetics, epigenetics, and environment. Gastroenterology 2004;127(2):485-492

92 Svyryd Y, Hernández-Molina G, Vargas F, Sánchez-Guerrero J, Segovia DA, Mutchinick OM. X chromosome monosomy in primary and overlapping autoimmune diseases. Autoimmun Rev 2012;11(5):301-304

93 Kelley J, Trowsdale J. Features of MHC and NK gene clusters. Transpl Immunol 2005;14(3-4):129-134

94 Invernizzi P, Battezzati PM, Crosignani A, et al. Peculiar HLA polymorphisms in Italian patients with primary biliary cirrhosis. J Hepatol 2003;38(4):401-406

95 Donaldson PT, Baragiotta A, Heneghan MA, et al. HLA class II alleles, genotypes, haplotypes, and amino acids in primary biliary cirrhosis: a large-scale study. Hepatology 2006;44(3):667-674

96 Donaldson PT. TNF gene polymorphisms in primary biliary cirrhosis: a critical appraisal. J Hepatol 1999;31(2):366-368

97 Juran BD, Hirschfield GM, Invernizzi P, et al; Italian PBC Genetics Study Group. Immunochip analyses identify a novel risk locus for primary biliary cirrhosis at 13q14, multiple independent associations at four established risk loci and epistasis between $1 \mathrm{p} 31$ and 7q32 risk variants. Hum Mol Genet 2012;21(23):5209-5221

98 Liu JZ, Almarri MA, Gaffney DJ, et al; UK Primary Biliary Cirrhosis (PBC) Consortium; Wellcome Trust Case Control Consortium 3. Dense fine-mapping study identifies new susceptibility loci for primary biliary cirrhosis. Nat Genet 2012;44(10):1137-1141

99 Umemura T, Joshita S, Ichijo T, et al; Shinshu PBC Study Group. Human leukocyte antigen class II molecules confer both susceptibility and progression in Japanese patients with primary biliary cirrhosis. Hepatology 2012;55(2):506-511

100 Invernizzi P, Ransom M, Raychaudhuri S, et al; Italian PBC Genetics Study Group. Classical HLA-DRB1 and DPB1 alleles account for HLA associations with primary biliary cirrhosis. Genes Immun 2012;13(6):461-468

101 Zhao DT, Liao HY, Zhang X, et al. Human leucocyte antigen alleles and haplotypes and their associations with antinuclear antibodies features in Chinese patients with primary biliary cirrhosis. Liver Int 2014;34(2):220-226

102 Mells GF, Kaser A, Karlsen TH. Novel insights into autoimmune liver diseases provided by genome-wide association studies. J Autoimmun 2013;46:41-54

103 Liu X, Invernizzi P, Lu Y, et al. Genome-wide meta-analyses identify three loci associated with primary biliary cirrhosis. Nat Genet 2010;42(8):658-660

104 Hirschfield GM, Liu X, Xu C, et al. Primary biliary cirrhosis associated with HLA, IL12A, and IL12RB2 variants. N Engl J Med 2009;360(24):2544-2555

105 Hirschfield GM, Siminovitch KA. Toward the molecular dissection of primary biliary cirrhosis. Hepatology 2009;50(5):1347-1350

106 Watford WT, Hissong BD, Bream JH, Kanno Y, Muul L, O'Shea JJ. Signaling by IL-12 and IL-23 and the immunoregulatory roles of STAT4. Immunol Rev 2004;202:139-156
107 Tamiya T, Kashiwagi I, Takahashi R, Yasukawa H, Yoshimura A. Suppressors of cytokine signaling (SOCS) proteins and JAK/STAT pathways: regulation of T-cell inflammation by SOCS1 and SOCS3. Arterioscler Thromb Vasc Biol 2011;31(5):980-985

$108 \mathrm{Hu} \mathrm{G}$, Barnes BJ. IRF-5 is a mediator of the death receptor-induced apoptotic signaling pathway. J Biol Chem 2009;284(5): 2767-2777

109 Krausgruber T, Blazek K, Smallie T, et al. IRF5 promotes inflammatory macrophage polarization and TH1-TH17 responses. Nat Immunol 2011;12(3):231-238

110 Zhang X, Ing S, Fraser A, et al. Follicular helper T cells: new insights into mechanisms of autoimmune diseases. Ochsner J 2013;13(1):131-139

111 Wang JH, Avitahl N, Cariappa A, et al. Aiolos regulates B cell activation and maturation to effector state. Immunity 1998;9(4): 543-553

112 Hirschfield GM, Xie G, Lu E, et al. Association of primary biliary cirrhosis with variants in the CLEC16A, SOCS1, SPIB and SIAE immunomodulatory genes. Genes Immun 2012;13(4): 328-335

113 Nakamura M, Nishida N, Kawashima M, et al. Genome-wide association study identifies TNFSF15 and POU2AF1 as susceptibility loci for primary biliary cirrhosis in the Japanese population. Am J Hum Genet 2012;91(4):721-728

114 Li M, Zheng H, Li T, Gao P, Zhang XL, Liu DW. Cytotoxic Tlymphocyte associated antigen-4 gene polymorphisms and primary biliary cirrhosis: a systematic review. J Gastroenterol Hepatol 2012;27(7):1159-1166

115 Donaldson P, Agarwal K, Craggs A, Craig W, James O, Jones D. HLA and interleukin 1 gene polymorphisms in primary biliary cirrhosis: associations with disease progression and disease susceptibility. Gut 2001;48(3):397-402

116 Vogel A, Strassburg CP, Manns MP. Genetic association of vitamin D receptor polymorphisms with primary biliary cirrhosis and autoimmune hepatitis. Hepatology 2002;35(1):126-131

117 Gianchecchi E, Palombi M, Fierabracci A. The putative role of the C1858T polymorphism of protein tyrosine phosphatase PTPN22 gene in autoimmunity. Autoimmun Rev 2013;12(7):717-725

118 Zheng J, Petersen F, Yu X. The role of PTPN22 in autoimmunity: learning from mice. Autoimmun Rev 2014;13(3):266-271

119 Zhou VW, Goren A, Bernstein BE. Charting histone modifications and the functional organization of mammalian genomes. Nat Rev Genet 2011;12(1):7-18

120 Bogdanos DP, Smyk DS, Rigopoulou EI, et al. Twin studies in autoimmune disease: genetics, gender and environment. J Autoimmun 2012;38(2-3):J156-J169

121 Costenbader KH, Gay S, Alarcón-Riquelme ME, Iaccarino L, Doria A. Genes, epigenetic regulation and environmental factors: which is the most relevant in developing autoimmune diseases? Autoimmun Rev 2012;11(8):604-609

122 Katoh H, Zheng P, Liu Y. FOXP3: genetic and epigenetic implications for autoimmunity. J Autoimmun 2013;41:72-78

123 Lu Q. The critical importance of epigenetics in autoimmunity. J Autoimmun 2013;41:1-5

124 Luo Y, Wang Y, Wang Q, Xiao R, Lu Q. Systemic sclerosis: genetics and epigenetics. J Autoimmun 2013;41:161-167

125 Wang Q, Selmi C, Zhou X, et al. Epigenetic considerations and the clinical reevaluation of the overlap syndrome between primary biliary cirrhosis and autoimmune hepatitis. J Autoimmun 2013; $41: 140-145$

126 Higuchi M, Horiuchi T, Kojima T, et al. Analysis of CD40 ligand gene mutations in patients with primary biliary cirrhosis. Scand J Clin Lab Invest 1998;58(5):429-432

127 Lleo A, Liao J, Invernizzi P, et al. Immunoglobulin M levels inversely correlate with CD40 ligand promoter methylation in patients with primary biliary cirrhosis. Hepatology 2012;55(1): 153-160 
128 Bianchi I, Lleo A, Gershwin ME, Invernizzi P. The X chromosome and immune associated genes. J Autoimmun 2012;38(2-3): J187-J192

129 Borchers AT, Gershwin ME. Sociological differences between women and men: implications for autoimmunity. Autoimmun Rev 2012;11(6-7):A413-A421

130 Lee TP, Chiang BL. Sex differences in spontaneous versus induced animal models of autoimmunity. Autoimmun Rev 2012;11(6-7): A422-A429

131 Moroni L, Bianchi I, Lleo A. Geoepidemiology, gender and autoimmune disease. Autoimmun Rev 2012;11(6-7):A386-A392

132 Nussinovitch $U$, Shoenfeld $Y$. The role of gender and organ specific autoimmunity. Autoimmun Rev 2012;11(6-7):A377-A385

133 Oertelt-Prigione $S$. The influence of sex and gender on the immune response. Autoimmun Rev 2012;11(6-7):A479-A485

134 Pennell LM, Galligan CL, Fish EN. Sex affects immunity. J Autoimmun 2012;38(2-3):J282-J291

135 Quintero OL, Amador-Patarroyo MJ, Montoya-Ortiz G, RojasVillarraga A, Anaya JM. Autoimmune disease and gender: plausible mechanisms for the female predominance of autoimmunity. J Autoimmun 2012;38(2-3):J109-J119

136 Rogers MA, Levine DA, Blumberg N, Fisher GG, Kabeto M, Langa KM. Antigenic challenge in the etiology of autoimmune disease in women. J Autoimmun 2012;38(2-3):J97-J102

137 Selmi C, Brunetta E, Raimondo MG, Meroni PL. The X chromosome and the sex ratio of autoimmunity. Autoimmun Rev 2012; 11(6-7):A531-A537

138 Shoenfeld Y, Tincani A, Gershwin ME. Sex gender and autoimmunity. J Autoimmun 2012;38(2-3):J71-J73

139 Amur S, Parekh A, Mummaneni P. Sex differences and genomics in autoimmune diseases. J Autoimmun 2012;38(2-3): J254-J265

140 Mitchell MM, Lleo A, Zammataro L, et al. Epigenetic investigation of variably $\mathrm{X}$ chromosome inactivated genes in monozygotic female twins discordant for primary biliary cirrhosis. Epigenetics 2011;6(1):95-102

141 Lleo A, Oertelt-Prigione S, Bianchi I, et al. Y chromosome loss in male patients with primary biliary cirrhosis. J Autoimmun 2013; 41:87-91

142 Podda M, Selmi C, Lleo A, Moroni L, Invernizzi P. The limitations and hidden gems of the epidemiology of primary biliary cirrhosis. J Autoimmun 2013;46:81-87

143 Padgett KA, Lan RY, Leung PC, et al. Primary biliary cirrhosis is associated with altered hepatic microRNA expression. J Autoimmun 2009;32(3-4):246-253

144 Qin B, Huang F, Liang Y, Yang Z, Zhong R. Analysis of altered microRNA expression profiles in peripheral blood mononuclear cells from patients with primary biliary cirrhosis. J Gastroenterol Hepatol 2013;28(3):543-550

145 Banales JM, Sáez E, Uriz M, et al. Up-regulation of microRNA 506 leads to decreased $\mathrm{Cl}-/ \mathrm{HCO}-$ anion exchanger 2 expression in biliary epithelium of patients with primary biliary cirrhosis. Hepatology 2012;56(2):687-697

146 Ninomiya M, Kondo Y, Funayama R, et al. Distinct microRNAs expression profile in primary biliary cirrhosis and evaluation of miR 505-3p and miR197-3p as novel biomarkers. PLoS ONE 2013; 8(6):e66086

147 Qian C, Chen SX, Ren CL, Zhong RQ, Deng AM, Qin Q. [Abnormal expression of miR-let-7b in primary biliary cirrhosis and its clinical significance]. Zhonghua Gan Zang Bing Za Zhi 2013; 21(7):533-536

148 Selmi C, Invernizzi P, Miozzo M, Podda M, Gershwin ME. Primary biliary cirrhosis: does X mark the spot? Autoimmun Rev 2004; 3(7-8):493-499

149 Bouman A, Heineman MJ, Faas MM. Sex hormones and the immune response in humans. Hum Reprod Update 2005;11(4): 411-423
150 Invernizzi P, Miozzo M, Battezzati PM, et al. Frequency of monosomy $\mathrm{X}$ in women with primary biliary cirrhosis. Lancet 2004; 363(9408):533-535

151 Borchers AT, Naguwa SM, Keen CL, Gershwin ME. The implications of autoimmunity and pregnancy. J Autoimmun 2010; 34(03):J287-J299

152 Bogdanos D, Pusl T, Rust C, Vergani D, Beuers U. Primary biliary cirrhosis following Lactobacillus vaccination for recurrent vaginitis. J Hepatol 2008;49(3):466-473

153 Selmi C, Lleo A, Pasini S, Zuin M, Gershwin ME. Innate immunity and primary biliary cirrhosis. Curr Mol Med 2009;9(1):45-51

154 Kikuchi K, Lian ZX, Yang GX, et al. Bacterial CpG induces hyperIgM production in $\mathrm{CD} 27(+)$ memory B cells in primary biliary cirrhosis. Gastroenterology 2005;128(2):304-312

155 Medzhitov R, Janeway CA Jr. Decoding the patterns of self and nonself by the innate immune system. Science 2002;296(5566): 298-300

156 Mogensen TH. Pathogen recognition and inflammatory signaling in innate immune defenses. Clin Microbiol Rev 2009;22(2): 240-273 Table of Contents

157 Mao TK, Lian ZX, Selmi C, et al. Altered monocyte responses to defined TLR ligands in patients with primary biliary cirrhosis. Hepatology 2005;42(4):802-808

158 Moritoki Y, Lian ZX, Wulff H, et al. AMA production in primary biliary cirrhosis is promoted by the TLR9 ligand CpG and suppressed by potassium channel blockers. Hepatology 2007;45(2): 314-322

159 Shimoda S, Harada K, Niiro H, et al. Interaction between Toll-like receptors and natural killer cells in the destruction of bile ducts in primary biliary cirrhosis. Hepatology 2011;53(4):1270-1281

160 Banchereau J, Briere F, Caux C, et al. Immunobiology of dendritic cells. Annu Rev Immunol 2000;18:767-811

161 Demetris AJ, Sever C, Kakizoe S, Oguma S, Starzl TE, Jaffe R. S100 protein positive dendritic cells in primary biliary cirrhosis and other chronic inflammatory liver diseases. Relevance to pathogenesis? Am J Pathol 1989;134(4):741-747

162 Tanimoto K, Akbar SM, Michitaka K, Onji M. Immunohistochemical localization of antigen presenting cells in liver from patients with primary biliary cirrhosis; highly restricted distribution of CD83-positive activated dendritic cells. Pathol Res Pract 1999; 195(3):157-162

163 Akbar SM, Yamamoto K, Miyakawa H, et al. Peripheral blood T-cell responses to pyruvate dehydrogenase complex in primary biliary cirrhosis: role of antigen-presenting dendritic cells. Eur J Clin Invest 2001;31(7):639-646

164 Kita H, Lian ZX, Van de Water J, et al. Identification of HLA-A2restricted $\mathrm{CD} 8(+)$ cytotoxic $\mathrm{T}$ cell responses in primary biliary cirrhosis: T cell activation is augmented by immune complexes cross-presented by dendritic cells. J Exp Med 2002;195(1): 113-123

165 Hiasa Y, Akbar SM, Abe M, Michitaka K, Horiike N, Onji M. Dendritic cell subtypes in autoimmune liver diseases; decreased expression of HLA DR and CD123 on type 2 dendritic cells. Hepatol Res 2002;22(4):241-249

166 Harada K, Shimoda S, Ikeda H, et al. Significance of periductal Langerhans cells and biliary epithelial cell-derived macrophage inflammatory protein-3. $\alpha$ in the pathogenesis of primary biliary cirrhosis. Liver Int 2011;31(2):245-253

167 Vandenbark AA, Meza-Romero R, Benedek G, et al. A novel regulatory pathway for autoimmune disease: binding of partial MHC class II constructs to monocytes reduces CD74 expression and induces both specific and bystander T-cell tolerance. J Autoimmun 2013;40:96-110

168 Honda Y, Yamagiwa S, Matsuda Y, Takamura M, Ichida T, Aoyagi Y. Altered expression of TLR homolog RP105 on monocytes hypersensitive to LPS in patients with primary biliary cirrhosis. J Hepatol 2007;47(3):404-411 
169 Takii Y, Nakamura M, Ito M, et al. Enhanced expression of type I interferon and toll-like receptor-3 in primary biliary cirrhosis. Lab Invest 2005;85(7):908-920

170 Jin JO, Han X, Yu Q. Interleukin-6 induces the generation of IL-10producing Tr1 cells and suppresses autoimmune tissue inflammation. J Autoimmun 2013;40:28-44

171 Samavedam UK, Kalies K, Scheller J, et al. Recombinant IL-6 treatment protects mice from organ specific autoimmune disease by IL-6 classical signalling-dependent IL-1ra induction. J Autoimmun 2013;40:74-85

172 Selmi C, Meroni PL, Gershwin ME. Primary biliary cirrhosis and Sjögren's syndrome: autoimmune epithelitis. J Autoimmun 2012; 39(1-2):34-42

173 Van den Oord JJ, Sciot R, Desmet VJ. Expression of MHC products by normal and abnormal bile duct epithelium. J Hepatol 1986; 3(3):310-317

174 Ayres RC, Neuberger JM, Shaw J, Joplin R, Adams DH. Intercellular adhesion molecule- 1 and $\mathrm{MHC}$ antigens on human intrahepatic bile duct cells: effect of pro-inflammatory cytokines. Gut 1993; 34(9):1245-1249

175 Leon MP, Bassendine MF, Gibbs P, Thick M, Kirby JA. Immunogenicity of biliary epithelium: study of the adhesive interaction with lymphocytes. Gastroenterology 1997;112(3):968-977

176 Tsuneyama K, Van de Water J, Leung PS, et al. Abnormal expression of the E2 component of the pyruvate dehydrogenase complex on the luminal surface of biliary epithelium occurs before major histocompatibility complex class II and BB1/B7 expression. Hepatology 1995;21(4):1031-1037

177 Ballardini G, Mirakian R, Bianchi FB, Pisi E, Doniach D, Bottazzo GF. Aberrant expression of HLA-DR antigens on bileduct epithelium in primary biliary cirrhosis: relevance to pathogenesis. Lancet 1984;2(8410):1009-1013

178 Cha S, Leung PS, Gershwin ME, Fletcher MP, Ansari AA, Coppel RL. Combinatorial autoantibodies to dihydrolipoamide acetyltransferase, the major autoantigen of primary biliary cirrhosis. Proc Natl Acad Sci U S A 1993;90(6):2527-2531

179 Borchers AT, Shimoda S, Bowlus C, Keen CL, Gershwin ME. Lymphocyte recruitment and homing to the liver in primary biliary cirrhosis and primary sclerosing cholangitis. Semin Immunopathol 2009;31(3):309-322

180 Sakisaka S, Gondo K, Yoshitake M, et al. Functional differences between hepatocytes and biliary epithelial cells in handling polymeric immunoglobulin A2 in humans, rats, and guinea pigs. Hepatology 1996;24(2):398-406

181 Fukushima N, Nalbandian G, Van De Water J, et al. Characterization of recombinant monoclonal IgA anti-PDC-E2 autoantibodies derived from patients with PBC. Hepatology 2002;36(6): 1383-1392

182 Johansson S, Berg L, Hall H, Höglund P. NK cells: elusive players in autoimmunity. Trends Immunol 2005;26(11):613-618

183 Panasiuk A, Prokopowicz D, Zak J. Peripheral blood T, B lymphocytes and NK cells in primary biliary cirrhosis. Rocz Akad Med Bialymst 2001;46:231-239

184 Chuang YH, Lian ZX, Tsuneyama K, et al. Increased killing activity and decreased cytokine production in NK cells in patients with primary biliary cirrhosis. J Autoimmun 2006; 26(4):232-240

185 Shimoda S, Tsuneyama K, Kikuchi K, et al. The role of natural killer (NK) and NK T cells in the loss of tolerance in murine primary biliary cirrhosis. Clin Exp Immunol 2012;168(3):279-284

186 Hudspeth K, Pontarini E, Tentorio P, et al. The role of natural killer cells in autoimmune liver disease: a comprehensive review. J Autoimmun 2013;46:55-65

187 Kita H, Naidenko OV, Kronenberg M, et al. Quantitation and phenotypic analysis of natural killer $\mathrm{T}$ cells in primary biliary cirrhosis using a human CD1d tetramer. Gastroenterology 2002; 123(4):1031-1043
188 Chuang YH, Lian ZX, Yang GX, et al. Natural killer T cells exacerbate liver injury in a transforming growth factor beta receptor II dominant-negative mouse model of primary biliary cirrhosis. Hepatology 2008;47(2):571-580

$189 \mathrm{Wu}$ SJ, Yang YH, Tsuneyama K, et al. Innate immunity and primary biliary cirrhosis: activated invariant natural killer T cells exacerbate murine autoimmune cholangitis and fibrosis. Hepatology 2011;53(3):915-925

190 Harada K, Van de Water J, Leung PS, et al. In situ nucleic acid hybridization of cytokines in primary biliary cirrhosis: predominance of the Th1 subset. Hepatology 1997;25(4):791-796

191 NaganoT, Yamamoto K, Matsumoto S, et al. Cytokine profile in the liver of primary biliary cirrhosis. J Clin Immunol 1999;19(6): 422-427

192 Lan RY, Salunga TL, Tsuneyama K, et al. Hepatic IL-17 responses in human and murine primary biliary cirrhosis. J Autoimmun 2009; 32(1):43-51

193 Trivedi PJ, Adams DH. Mucosal immunity in liver autoimmunity: a comprehensive review. J Autoimmun 2013;46:97-111

194 Fenoglio D, Bernuzzi F, Battaglia F, et al. Th17 and regulatory T lymphocytes in primary biliary cirrhosis and systemic sclerosis as models of autoimmune fibrotic diseases. Autoimmun Rev 2012; 12(2):300-304

195 Lan RY, Cheng C, Lian ZX, et al. Liver-targeted and peripheral blood alterations of regulatory $\mathrm{T}$ cells in primary biliary cirrhosis. Hepatology 2006;43(4):729-737

196 Zhang W, Sharma R, Ju ST, et al. Deficiency in regulatory T cells results in development of antimitochondrial antibodies and autoimmune cholangitis. Hepatology 2009;49(2):545-552

197 Mayer CT, Tian L, Hesse C, et al. Anti-CD4 treatment inhibits autoimmunity in scurfy mice through the attenuation of costimulatory signals. J Autoimmun 2014;50:23-32

198 Bernuzzi F, Fenoglio D, Battaglia F, et al. Phenotypical and functional alterations of $\mathrm{CD} 8$ regulatory T cells in primary biliary cirrhosis. J Autoimmun 2010;35(3):176-180

199 Oertelt-Prigione S, Mao TK, Selmi C, et al. Impaired indoleamine 2,3-dioxygenase production contributes to the development of autoimmunity in primary biliary cirrhosis. Autoimmunity 2008; 41(1):92-99

200 Selmi C, Podda M, Gershwin ME. Old and rising stars in the lymphoid liver. Semin Immunopathol 2009;31(3):279-282

201 Shimoda S, Van de Water J, Ansari A, et al. Identification and precursor frequency analysis of a common $T$ cell epitope motif in mitochondrial autoantigens in primary biliary cirrhosis. J Clin Invest 1998;102(10):1831-1840

202 Shimoda S, Harada K, Niiro H, et al. Biliary epithelial cells and primary biliary cirrhosis: the role of liver-infiltrating mononuclear cells. Hepatology 2008;47(3):958-965

203 Shimoda S, Ishikawa F, Kamihira T, et al. Autoreactive T-cell responses in primary biliary cirrhosis are proinflammatory whereas those of controls are regulatory. Gastroenterology 2006;131(2):606-618

204 Shimoda S, Miyakawa H, Nakamura M, et al. CD4 T-cell autoreactivity to the mitochondrial autoantigen PDC-E2 in AMA-negative primary biliary cirrhosis. J Autoimmun 2008;31(2):110-115

205 Shimoda S, Nakamura M, Ishibashi H, Hayashida K, Niho Y. HLA DRB4 0101-restricted immunodominant $\mathrm{T}$ cell autoepitope of pyruvate dehydrogenase complex in primary biliary cirrhosis: evidence of molecular mimicry in human autoimmune diseases. J Exp Med 1995;181(5):1835-1845

206 Shimoda S, Nakamura M, Ishibashi H, et al. Molecular mimicry of mitochondrial and nuclear autoantigens in primary biliary cirrhosis. Gastroenterology 2003;124(7):1915-1925

207 Shimoda S, Nakamura M, Shigematsu H, et al. Mimicry peptides of human PDC-E2 163-176 peptide, the immunodominant T-cell epitope of primary biliary cirrhosis. Hepatology 2000;31(6): $1212-1216$ 
208 Kita H, Matsumura S, He XS, et al. Quantitative and functional analysis of PDC-E2-specific autoreactive cytotoxic T lymphocytes in primary biliary cirrhosis. J Clin Invest 2002;109(9):1231-1240

209 Chabot S, Fakhfakh A, Béland K, et al. Mouse liver-specific CD8(+) T-cells encounter their cognate antigen and acquire capacity to destroy target hepatocytes. J Autoimmun 2013;42:19-28

210 Tanaka A, Nezu S, Uegaki S, et al. The clinical significance of IgA antimitochondrial antibodies in sera and saliva in primary biliary cirrhosis. Ann N Y Acad Sci 2007;1107:259-270

211 Kim WR, Poterucha JJ, Jorgensen RA, et al. Does antimitochondrial antibody status affect response to treatment in patients with primary biliary cirrhosis? Outcomes of ursodeoxycholic acid therapy and liver transplantation. Hepatology 1997;26(1): $22-26$

212 Invernizzi P, Crosignani A, Battezzati PM, et al. Comparison of the clinical features and clinical course of antimitochondrial antibody-positive and -negative primary biliary cirrhosis. Hepatology 1997;25(5):1090-1095

213 Cambridge G, Perry HC, Nogueira L, et al. The effect of B-cell depletion therapy on serological evidence of B-cell and plasmablast activation in patients with rheumatoid arthritis over multiple cycles of rituximab treatment. J Autoimmun 2014; 50:67-76

214 Moritoki Y, Lian ZX, Ohsugi Y, Ueno Y, Gershwin ME. B cells and autoimmune liver diseases. Autoimmun Rev 2006;5(7):449-457

215 Takahashi T, Miura T, Nakamura J, et al. Plasma cells and the chronic nonsuppurative destructive cholangitis of primary biliary cirrhosis. Hepatology 2012;55(3):846-855

216 Moritoki Y, Lian ZX, Lindor K, et al. B-cell depletion with antiCD20 ameliorates autoimmune cholangitis but exacerbates colitis in transforming growth factor-beta receptor II dominant negative mice. Hepatology 2009;50(6):1893-1903

217 Tsuda M, Moritoki Y, Lian ZX, et al. Biochemical and immunologic effects of rituximab in patients with primary biliary cirrhosis and an incomplete response to ursodeoxycholic acid. Hepatology 2012;55(2):512-521

218 Dhirapong A, Lleo A, Yang GX, et al. B cell depletion therapy exacerbates murine primary biliary cirrhosis. Hepatology 2011; 53(2):527-535

219 Angulo P, Jorgensen RA, Keach JC, Dickson ER, Smith C, Lindor KD. Oral budesonide in the treatment of patients with primary biliary cirrhosis with a suboptimal response to ursodeoxycholic acid. Hepatology 2000;31(2):318-323

220 Kaplan MM, Bonder A, Ruthazer R, Bonis PA. Methotrexate in patients with primary biliary cirrhosis who respond incompletely to treatment with ursodeoxycholic acid. Dig Dis Sci 2010;55(11): 3207-3217

221 Munoz SJ. Cyclosporine in primary biliary cirrhosis. N Engl J Med 1990;323(19):1352

222 Gong Y, Christensen E, Gluud C. Azathioprine for primary biliary cirrhosis. Cochrane Database Syst Rev 2007;(3):CD006000

223 Wolfraim LA. Treating autoimmune diseases through restoration of antigen-specific immune tolerance. Arch Immunol Ther Exp (Warsz) 2006;54(1):1-13

224 Yin YF, Zhang X. B cell depletion in treating primary biliary cirrhosis: pros and cons. World J Gastroenterol 2012;18(30): 3938-3940

225 Kawata K, Tsuda M, Yang GX, et al. Identification of potential cytokine pathways for therapeutic intervention in murine primary biliary cirrhosis. PLoS ONE 2013;8(9):e74225

226 Cingoz O. Ustekinumab. MAbs 2009;1(3):216-221

227 Kavanaugh A, Ritchlin C, Rahman P, et al; PSUMMIT-1 and 2 Study Groups. Ustekinumab, an anti-IL-12/23 p40 monoclonal antibody, inhibits radiographic progression in patients with active psoriatic arthritis: results of an integrated analysis of radiographic data from the phase 3, multicentre, randomised, double-blind, placebo-controlled PSUMMIT-1 and PSUMMIT-2 trials. Ann Rheum Dis 2014;73(6):1000-1006
228 Antonelli A, Ferrari SM, Giuggioli D, Ferrannini E, Ferri C, Fallahi P. Chemokine (C-X-C motif) ligand (CXCL)10 in autoimmune diseases. Autoimmun Rev 2014;13(3):272-280

229 Chuang YH, Lian ZX, Cheng CM, et al. Increased levels of chemokine receptor CXCR3 and chemokines IP-10 and MIG in patients with primary biliary cirrhosis and their first degree relatives. J Autoimmun 2005;25(2):126-132

230 Dhirapong A, Yang GX, Nadler S, et al. Therapeutic effect of cytotoxic $\mathrm{T}$ lymphocyte antigen 4/immunoglobulin on a murine model of primary biliary cirrhosis. Hepatology 2013;57(2):708-715

231 Romo-Tena J, Gómez-Martín D, Alcocer-Varela J. CTLA-4 and autoimmunity: new insights into the dual regulator of tolerance. Autoimmun Rev 2013;12(12):1171-1176

232 Walker LS. Treg and CTLA-4: two intertwining pathways to immune tolerance. J Autoimmun 2013;45:49-57

233 Figueroa FE, Carrión F, Villanueva S, Khoury M. Mesenchymal stem cell treatment for autoimmune diseases: a critical review. Biol Res 2012;45(3):269-277

234 Wang D, Zhang H, Liang J, et al. Effect of allogeneic bone marrowderived mesenchymal stem cells transplantation in a polyl:Cinduced primary biliary cirrhosis mouse model. Clin Exp Med 2011;11(1):25-32

235 Wang L, Li J, Liu H, et al. Pilot study of umbilical cord-derived mesenchymal stem cell transfusion in patients with primary biliary cirrhosis. J Gastroenterol Hepatol 2013;28(Suppl 1):85-92

236 Van Brussel I, Lee WP, Rombouts M, et al. Tolerogenic dendritic cell vaccines to treat autoimmune diseases: can the unattainable dream turn into reality? Autoimmun Rev 2014;13(2):138-150

237 Weiner HL. Oral tolerance: immune mechanisms and treatment of autoimmune diseases. Immunol Today 1997;18(7):335-343

238 Suzuki A, Van de Water J, Gershwin ME, Jorgensen R, Angulo P, Lindor K. Oral tolerance and pyruvate dehydrogenase in patients with primary biliary cirrhosis. Dev Immunol 2002;9(2):55-61

239 Goudy KS, Annoni A, Naldini L, Roncarolo MG. Manipulating immune tolerance with micro-RNA regulated gene therapy. Front Microbiol 2011;2:221

240 Pauley KM, Cha S. RNAi therapeutics in autoimmune disease. Pharmaceuticals (Basel) 2013;6(3):287-294

241 Ando Y, Yang GX, Kenny TP, et al. Overexpression of microRNA-21 is associated with elevated pro-inflammatory cytokines in dominant-negative TGF- $\beta$ receptor type II mouse. J Autoimmun 2013; 41:111-119

242 Singh RP, Massachi I, Manickavel S, et al. The role of miRNA in inflammation and autoimmunity. Autoimmun Rev 2013;12(12): 1160-1165

243 Albani S, Koffeman EC, Prakken B. Induction of immune tolerance in the treatment of rheumatoid arthritis. Nat Rev Rheumatol 2011;7(5):272-281

244 Imam MH, Talwalkar JA, Lindor KD. Clinical management of autoimmune biliary diseases. J Autoimmun 2013;46:88-96

245 Bogdanos DP, Baum H, Sharma UC, et al. Antibodies against homologous microbial caseinolytic proteases $\mathrm{P}$ characterise primary biliary cirrhosis. J Hepatol 2002;36(1):14-21

246 Kaplan MM. Novosphingobium aromaticivorans: a potential initiator of primary biliary cirrhosis. Am J Gastroenterol 2004;99(11): 2147-2149

247 Goo MJ, Ki MR, Lee HR, et al. Primary biliary cirrhosis, similar to that in human beings, in a male C57BL/6 mouse infected with Helicobacter pylori. Eur J Gastroenterol Hepatol 2008;20(10):1045-1048

248 Bogdanos DP, Baum H, Gunsar F, et al. Extensive homology between the major immunodominant mitochondrial antigen in primary biliary cirrhosis and Helicobacter pylori does not lead to immunological cross-reactivity. Scand J Gastroenterol 2004; 39(10):981-987

249 Bogdanos DP, Baum H, Okamoto M, et al. Primary biliary cirrhosis is characterized by IgG3 antibodies cross-reactive with the major mitochondrial autoepitope and its Lactobacillus mimic. Hepatology 2005;42(2):458-465 
250 Berg CP, Kannan TR, Klein R, et al. Mycoplasma antigens as a possible trigger for the induction of antimitochondrial antibodies in primary biliary cirrhosis. Liver Int 2009;29(6):797-809

251 Bogdanos DP, Pares A, Baum H, et al. Disease-specific cross-reactivity between mimicking peptides of heat shock protein of Mycobacterium gordonae and dominant epitope of E2 subunit of pyruvate dehydrogenase is common in Spanish but not British patients with primary biliary cirrhosis. J Autoimmun 2004;22(4):353-362

252 Bogdanos DP, Koutsoumpas A, Baum H, Vergani D. Borrelia burgdorferi: a new self-mimicking trigger in primary biliary cirrhosis. Dig Liver Dis 2006;38(10):781-782, author reply 782-783
253 Zhao J, Zhao S, Zhou G, et al. Altered biliary epithelial cell and monocyte responses to lipopolysaccharide as a TLR ligand in patients with primary biliary cirrhosis. Scand J Gastroenterol 2011;46(4):485-494

254 Nakamura M, Ishibashi H, Matsui M, et al. Peripheral B lymphocyte repertoire to mitochondrial antigen in primary biliary cirrhosis-positive correlation between the disease activity and the frequency of circulating B lymphocytes specific for pyruvate dehydrogenase complex. Autoimmunity 1995;21(4):253-262

255 Silveira MG, Lindor KD. Obeticholic acid and budesonide for the treatment of primary biliary cirrhosis. Expert Opin Pharmacother 2014;15(3):365-372 